\title{
Salusin- $\beta$ Is Involved in Diabetes Mellitus-Induced Endothelial Dysfunction via Degradation of Peroxisome Proliferator-Activated Receptor Gamma
}

\author{
Hai-Jian Sun,, ${ }^{1,2}$ Dan Chen, ${ }^{1}$ Pei-Yao Wang, ${ }^{2}$ Ming-Yu Wan, ${ }^{2}$ Chen-Xing Zhang, \\ Zhi-Xuan Zhang, ${ }^{2}$ Wei Lin, ${ }^{2}$ and Feng Zhang ${ }^{1}$ \\ ${ }^{1}$ Department of Physiology, Nanjing Medical University, Nanjing, Jiangsu 211166, China \\ ${ }^{2}$ Department of Basic Medicine, Wuxi School of Medicine, Jiangnan University, Wuxi, Jiangsu 214122, China \\ Correspondence should be addressed to Feng Zhang; fzhangnjmu@sina.com
}

Received 22 July 2017; Accepted 8 October 2017; Published 19 November 2017

Academic Editor: Eric E. Kelley

Copyright (C) 2017 Hai-Jian Sun et al. This is an open access article distributed under the Creative Commons Attribution License, which permits unrestricted use, distribution, and reproduction in any medium, provided the original work is properly cited.

\begin{abstract}
The pathophysiological mechanisms for vascular lesions in diabetes mellitus (DM) are complex, among which endothelial dysfunction plays a vital role. Therapeutic target against endothelial injury may provide critical venues for treatment of diabetic vascular diseases. We recently identified that salusin- $\beta$ contributed to high glucose-induced endothelial cell apoptosis. However, the roles of salusin- $\beta$ in DM-induced endothelial dysfunction remain largely elusive. Male C57BL/6J mice were used to induce type 2 diabetes mellitus (T2DM) model. Human umbilical vein endothelial cells (HUVECs) were cultured in high glucose/high fat (HG/HF) medium. We demonstrated increased expression of salusin- $\beta$ in diabetic aortic tissues and high-glucose/high-fat- (HG/HF-) incubated HUVECs. Disruption of salusin- $\beta$ by shRNA abrogated the reactive oxygen species (ROS) production, inflammation, and nitrotyrosine content of HUVECs cultured in HG/HF medium. The HG/HF-mediated decrease in peroxisome proliferator-activated receptor $\gamma$ (PPAR $\gamma$ ) expression was restored by salusin- $\beta$ shRNA, and PPAR $\gamma$ inhibitor T0070907 abolished the protective actions of salusin- $\beta$ shRNA on endothelial injury in HG/ HF-treated HUVECs. Salusin- $\beta$ silencing obviously improved endothelium-dependent vasorelaxation, oxidative stress, inflammatory response, and nitrative stress in diabetic aorta. Taken together, our results highlighted the essential role of salusin- $\beta$ in pathological endothelial dysfunction, and salusin- $\beta$ may be a promising target in treatment of vascular complications of DM.
\end{abstract}

\section{Introduction}

Type 2 diabetes mellitus (T2DM) is a tremendous threat to human health around the world $[1,2]$. Patients with DM had higher risk for cardiovascular events and complications than nondiabetic patients [3]. The impaired function in endothelium is critically involved in many cardiovascular disorders such as atherosclerosis, hypertension, and DM [4]. Endothelial dysfunction is a core event in the development of DM and determines future vascular diseases' complications [5]. Improvement of endothelial dysfunction may be an attractive therapeutic strategy for treatment of DMrelated cardiovascular disorders [4]. Decreased nitric oxide (NO) bioavailability is one of the earliest pathologic events that contributes to the development and progression of diabetic vascular complications [6]. It is well accepted that $\mathrm{NADPH}$ oxidase-derived reactive oxygen species (ROS) are requisite mediators of vascular injury in diabetes $[7,8]$. Nitrative stress (excessive production of $\mathrm{NO}$ and peroxynitrite) is presented in diabetic aorta, which leads to endothelial dysfunction [9-11]. Chronic inflammation in endothelial cells is associated with endothelial function disruption in DM $[12,13]$.

Salusin- $\beta$ is an endogenous bioactive peptide with 20 amino acid residues [14]. Salusin- $\beta$ stimulates the proliferation, migration of vascular smooth muscle cells (VSMCs), vascular fibrosis, and foam cell formation of VSMCs [15-17]. Salusin- $\beta$ acts as a potential proatherogenic factor via 
promoting macrophage foam cell formation [18]. Central microinjection of salusin- $\beta$ contributes to sympathetic activation, norepinephrine release, and hypertension [19-22]. The positive stains for salusin- $\beta$ have been detected in vasculature including endothelium [23]. Salusin- $\beta$ blockade ameliorates endothelial inflammation to improve pulmonary arterial hypertension and pulmonary vascular remodeling [24]. Plasma salusin- $\beta$ levels are higher in subjects with DM than healthy controls [25]. A recent study reveals that inhibition of salusin- $\beta$ alleviates oxidative stress, inflammation, and cardiac dysfunction in diabetic rats [26]. Furthermore, we recently identified that salusin- $\beta$ contributed to high glucose-induced inhibition of proliferation, migration, and angiogenesis in endothelial cells [27]. Up to now, the molecular link between salusin- $\beta$ and DM-related endothelial injury has yet to be fully clarified. Therefore, we investigated the potential roles of salu$\sin -\beta$ in endothelial dysfunction in DM and the underlying molecular mechanisms.

\section{Material and Methods}

2.1. Animals and Experimental Groups. Male C57BL/6J mice aged 6 weeks (Vital River Biological, Beijing, China) were used to induce type 2 diabetic model. All experiments were conformed to the rules and regulations of the Experimental Animal Care and Use Committee of Jiangnan University. All experiments adhered to the Care and Use of Laboratory Animal published by the US National Institutes of Health (NIH publication, 8th edition, 2011). The mice were housed on 12:12 hour light-dark cycle in a temperature-controlled and humidity-controlled room, with free access to standard chow and tap water. The animal model for type 2 diabetes in mice was made as previously described [28-30]. In brief, a combination of low-dose streptozotocin (STZ) and a high-fat diet (HFD) was applied to make an ideal animal model for type 2 diabetes in mice. After 2 weeks of acclimatization, all mice were randomly divided into four groups ( $n=8$ for each group). Two groups of mice received an intraperitoneal injection of vehicle and were fed with a normal diet $(14.7 \mathrm{~kJ} / \mathrm{g}, 13 \%$ of energy as fat) for 10 weeks. Another two groups of mice were subject to $4 \mathrm{~h}$ fasting and then were subjected to intraperitoneal injection of low-dose streptozotocin (STZ, $120 \mathrm{mg} / \mathrm{kg}$ body weight in $10 \mathrm{mmol} / \mathrm{l}$ citrate buffer, $\mathrm{pH} 4.0$ ); the normal diet was replaced with high-fat diet $(21.8 \mathrm{~kJ} / \mathrm{g}, 60 \%$ of energy as fat; D12492, Research Diets, New Brunswick, NJ, USA) for 7 weeks three weeks after injection of STZ. Eight weeks after the injection of STZ, the mice in control and diabetic mice received intravenous injection of adenoviral vectors encoding scramble shRNA (Ad-Scr-shRNA, $2.0 \times 10^{10}$ plaque-forming units) or adenoviral vectors encoding salusin- $\beta$ shRNA (Ad-Salusin- $\beta$ shRNA, $2.0 \times 10^{10}$ plaque-forming units). The Ad-Scr shRNA and Ad-Salusin- $\beta$ shRNA were constructed and purchased from Genomeditech Co. (Shanghai, China). Two weeks after introduction of Ad-Scr shRNA and AdSalusin- $\beta$ shRNA, all mice were euthanized with an overdose of pentobarbital sodium ( $150 \mathrm{mg} / \mathrm{kg}$, i.v.). The body weight or fasting blood glucose was measured at the end of experiments before sacrifice. The measurement for insulin tolerance test (ITT) and glucose tolerance test (GTT) in each mouse was conducted as in our previous reports $[26,28,30]$.

2.2. Evaluation of Vasorelaxation. Endothelial function was assessed by the vasorelaxation response to acetylcholine (ACh), an endothelium-dependent vasodilator, with that of sodium nitroprusside (SNP), an endothelium-independent vasodilator, respectively. In brief, the aorta from mice was collected in ice-cold physiological saline solution (PSS) and cut into 4 rings of $1 \mathrm{~mm}$ in length. The aortic rings were mounted onto two stainless steel wires and installed on a wire myograph (Model 620M, Danish Myo Technology, Aarhus, Denmark), filled with $5 \mathrm{ml}$ PSS buffer aerated with $95 \% \mathrm{O}_{2}$ and $5 \% \mathrm{CO}_{2}$ at $37^{\circ} \mathrm{C}$, which linked to transducers to recorded data. The artery segments were equilibrated for $60 \mathrm{~min}$ with an optimal initial tension before the experiments were started. After equilibration, aortic rings were contracted by phenylephrine $(\mathrm{PE}, 1 \mu \mathrm{M})$ to obtain similar precontraction among different groups. Once a stable contraction was achieved, the rings were exposed to cumulative concentrations of $\mathrm{ACh}\left(10^{-9}\right.$ to $\left.10^{-4} \mathrm{M}\right)$. The aortic rings were then washed and equilibrated to baseline levels, and the procedure was repeated with SNP of $10^{-9}$ to $10^{-5} \mathrm{M}$. Relaxation at each concentration was presented as the percentage of force generated in response to $\mathrm{PE}[31-33]$.

2.3. Cell Culture. Human umbilical vein endothelial cells (HUVECs) were cultured in RPMI 1640 medium supplemented with $10 \%$ fetal bovine serum, 100 units $/ \mathrm{ml}$ penicillin, and $100 \mu \mathrm{g} / \mathrm{ml}$ streptomycin under a condition at $37^{\circ} \mathrm{C}$ in a humidified air containing $5 \% \mathrm{CO}_{2}$. In order to mimic the increased glucose level in diabetes, HUVECs were cultured in high glucose/high fat (HG/HF) medium, containing glucose $(25 \mathrm{mM})$ and saturated free fatty acid (FFA) palmitate $(16: \mathrm{C} ; 500 \mu \mathrm{M}$, Sigma, USA) for $24 \mathrm{~h}$ according to the previous reports $[9,34]$. For in vitro studies, HUVECs were subcultured in six-well plates and transfected with Ad-Scr shRNA and Ad-Salusin- $\beta$ shRNA $\left(1 \times 10^{8}\right.$ plaque-forming units/ml) for $24 \mathrm{~h}$ as previously described [35].

2.4. Immunofluorescence Staining. After fixed with $4 \%$ paraformaldehyde for $30 \mathrm{~min}$, HUVECs were permeabilized with $0.1 \%$ Triton X-100 in PBS for 15 min. Cells were blocked with $5 \%$ bovine serum albumin (BSA) for $1 \mathrm{~h}$ at room temperature and then incubated with indicated anti-nitrotyrosine antibody at $4^{\circ} \mathrm{C}$ overnight. After three washes with PBS, cells were detected with goat anti-rabbit IgG H\&L Alexa Fluor ${ }^{\circledR}$ 488. Finally, nuclei were stained with 4,6-diamidino-2phenylindole (DAPI) for $10 \mathrm{~min}$. Images were acquired by a fluorescence microscope (80i, Nikon, Tokyo, Japan).

2.5. Immunohistochemistry Staining. The thoracic aorta was rinsed with cool sterile phosphate buffered saline (PBS). Paraffin-embedded heart and blood vessel sections $(5 \mu \mathrm{m})$ were permeabilized using $0.1 \%$ Triton X-100 for 10 min after deparaffinization and rehydration. The sections were washed in PBS then blocked with $10 \%$ goat serum for $1 \mathrm{~h}$, then incubated with rabbit anti-salusin- $\beta$ antibody overnight at $4^{\circ} \mathrm{C}$, 
and were then visualized under a Nikon microscope digital camera system (Nikon, Tokyo, Japan).

2.6. Enzyme-Linked Immunosorbent (ELISA) Assay. ELISA assays were performed to measure salusin- $\beta$ level in stimulated HUVECs according to the manufacturer's protocols (USCN Life Science, Houston, TX, USA). The protein levels of TNF- $\alpha$, IL- $1 \beta$, VCAM-1, and MCP-1 in medium supernatant from each sample were detected by commercial ELISA kits (BOSTER, Wuhan, China) according to the manufacturer's instructions as previously described [36, 37]. The blanks, diluted standards, or samples were added appropriately into coat wells in 96-well plates and HRPconjugated antibody was coincubated at $37^{\circ} \mathrm{C}$ for $30 \mathrm{~min}$. The reaction system was terminated with stopped solution, and the absorbance was determined using a microplate reader (STNERGY/H4, BioTek, Vermont, USA).

2.7. Real-Time PCR. Total RNA was extracted using TRIzol reagent according to the manufacturer's instructions. The equal RNA was used to generate cDNA using a first-strand cDNA Synthesis Kit (CWBIO, Taizhou, Jiangsu, China). The real-time quantitative PCR was performed in triplicates by using SYBR ${ }^{\circledR}$ mixture (CWBIO, Taizhou, Jiangsu, China). The average cycle thresholds $(\mathrm{Ct})$ were employed to quantify fold change. The $2^{-\triangle \triangle \mathrm{CT}}$ method was reported to calculate relative gene expression levels. The primer sequences used for real-time PCR were listed in the supplemental table (Tables S1 and S2 available online at https://doi.org/10. 1155/2017/6905217).

2.8. Western Blot. The protein in collected HUVECs or aorta was extracted in RIPA lysis, and equal amounts of total proteins electrophoresed, blotted, and then incubated with required primary antibodies including endothelial nitric oxide synthase (eNOS), phosphorylated-eNOS (p-eNOS), inducible nitric oxide synthase (iNOS), nitrotyrosine, NOX-2, $\mathrm{p} 22^{\text {phox }}, \mathrm{p} 47^{\text {phox }}$, peroxisome proliferatoractivated receptor $\gamma(\operatorname{PPAR} \gamma)$, glyceraldehyde phosphate dehydrogenase (GAPDH), interleukin-1 $\beta$ (IL-1 $\beta$ ), monocyte chemoattractant protein 1 (MCP-1), tumor necrosis factor- $\alpha$ (TNF- $\alpha)$, and vascular cellular adhesion molecule-1 (VCAM-1) at $4^{\circ} \mathrm{C}$ overnight. The blots were then incubated with appropriate secondary horseradish peroxidase- (HRP-) conjugated antibodies, and the immunoreactive proteins were visualized by enhanced chemiluminescence (Millipore Darmstadt, Germany).

2.9. Intracellular ROS Measurement. The collected HUVECs or aorta sections were fixed and treated with dihydroethidium (DHE, $10 \mu \mathrm{M}$ ) or $2^{\prime}, 7^{\prime}$-dichlorofluorescin diacetate (DCFH-DA, $10 \mu \mathrm{M}$ ) for $20 \mathrm{~min}$ at $37^{\circ} \mathrm{C}$, respectively. The fluorescence signals were captured with a multidetection microplate reader and quantified with the Image-Pro Plus 6.0 (version 6.0, Media Cybernetics, Bethesda, MD, USA) by using the same parameters [16].

2.10. Total NO Production and Nitrotyrosine Content Measurement. The total basal NOx (NO and its oxidative metabolic products, $\mathrm{NO}_{2}^{-}$and $\mathrm{NO}_{3}{ }^{-}$) production was detected by a NO detection kit (Beyotime Biotech Inc., Nanjing, China) was used following the instructions by the manufacturer. The total aortic proteins were measured using a BCA protein assay kit (Beyotime Institute of Biotechnology, China). NO data was expressed in $\mathrm{nM} / \mathrm{mg}$ protein $[9,31]$. The determination of nitrotyrosine content, which is taken as an index of protein nitration and nitrative stress, was performed with the aid of a Nitrotyrosine Assay Kit (Millipore, MA, USA) according to the manufacturer's instruction. Nitrotyrosine level was presented as $\mathrm{pM} / \mathrm{mg}$ protein [6,9].

2.11. Assay of eNOS Activity. The activity of eNOS in collected HUVECs was assessed by the conversion of L-arginine to NO using a Nitric Oxide Synthase Assay Kit (Beyotime Biotech Inc., Nanjing, China) as previously described $[38,39]$.

2.12. Chemicals. HUVECs were purchased from American Type Culture Collection (Rockville, MD, USA). Nitric Oxide Synthase Assay Kit, DHE, and DCFH-DA were obtained from Beyotime Institute of Biotechnology (Shanghai, China). Antibodies against eNOS, p-eNOS, and iNOS were obtained from Cell Signaling Technology (Beverly, MA, USA). Antibodies against nitrotyrosine, NOX-2, p22 $2^{\text {phox }}, \mathrm{p} 47^{\text {phox }}$, and goat anti-rabbit IgG H\&L (Alexa Fluor 488) were purchased from Abcam (Cambridge, MA, USA). Antibody against salu$\sin -\beta$ was obtained from Bachem (Bubendorf, Switzerland). Antibodies against PPAR $\gamma$, GAPDH, IL- $1 \beta$, MCP-1, TNF- $\alpha$, and VCAM-1 and HRP-conjugated secondary antibodies were purchased from Proteintech Group Inc. (Wuhan, China). 2-Chloro-5-nitro-N-4-pyridinyl-benzamide (T0070907) was purchased from Cayman Chemical Co. (Ann Arbor, MI, USA). The specific primers were synthesized by Sangon Biotech Co. Ltd. (Shanghai, China).

2.13. Statistical Analysis. All results were defined as mean \pm SE. Comparisons within two groups were made by Student's $t$-test. Statistical analysis was performed by ANOVA/Dunnet $t$-test for multiple group comparisons. The criterion for statistical significance was set at $P<0.05$.

\section{Results}

3.1. HG/HF Induced Salusin- $\beta$ Expression in HUVECs. Immunofluorescence staining showed the upregulated salusin- $\beta$ expression in HUVECs exposed to $\mathrm{HG} / \mathrm{HF}$ for $24 \mathrm{~h}$ (Figure S1(a)). HG/HF treatment not only enhanced salusin- $\beta$ protein expression (Figure S1(b)) but also elevated salusin- $\beta$ mRNA level (Figure S1(c)) in HUVECs, as detected by ELISA or real-time PCR, respectively. These results revealed that $\mathrm{HG} / \mathrm{HF}$ is an inducer of salusin- $\beta$ expression in HUVECs.

3.2. Salusin- $\beta$ Blockade Rectified Oxidative Stress in HUVECs. $\mathrm{HG} / \mathrm{HF}$ caused the overproduction of ROS in HUVECs as evidenced by DHE (Figures 1(a) and 1(b)) or DCFH-DA (Figures 1(a) and 1(c)) fluorescent dye, which was abrogated by inhibition of salusin- $\beta$. The upregulated protein expressions of NADPH oxidase subunits $\mathrm{p} 22^{\text {phox }}$ (Figures $1(\mathrm{~d})$ 

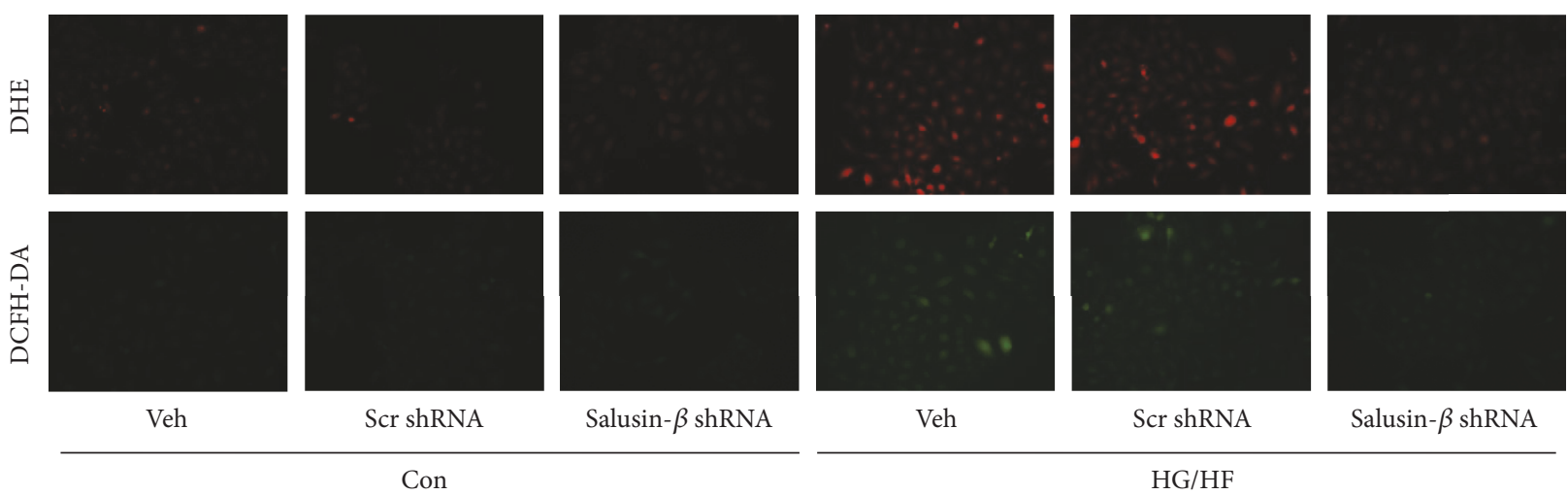

Salusin- $\beta$ shRNA

Veh

Scr shRNA

Salusin- $\beta$ shRNA

HG/HF

(a)

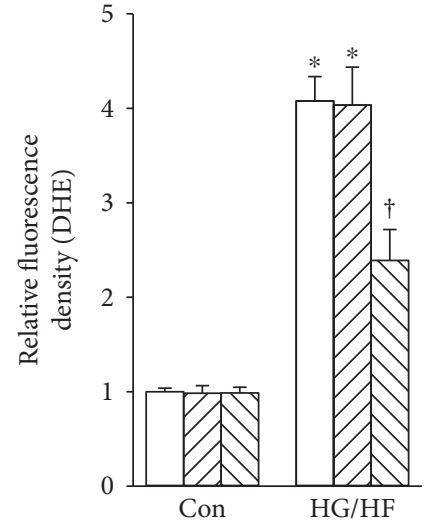

$\square$ Veh

$\square$ Scr shRNA

$\square$ Salusin- $\beta$ shRNA

(b)

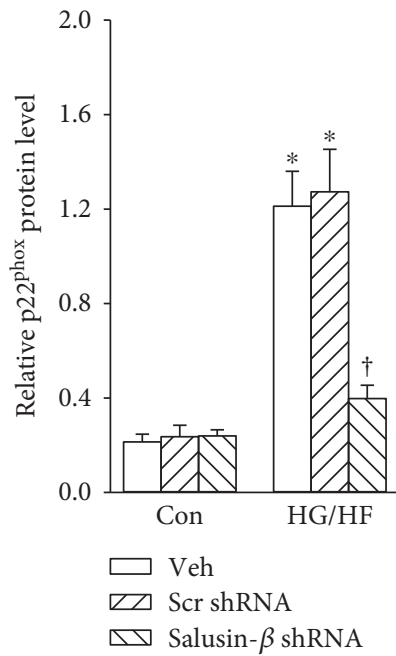

(e)

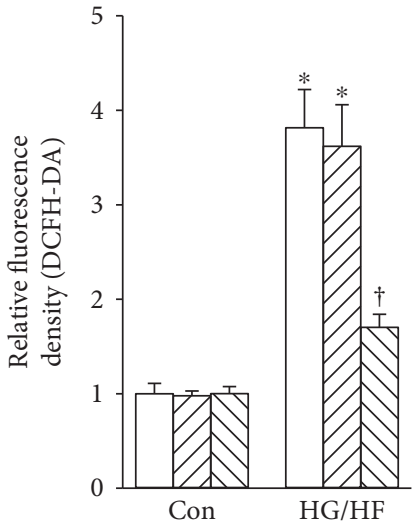

$\square$ Veh

Z Scr shRNA

$\triangle$ Salusin- $\beta$ shRNA

(c)

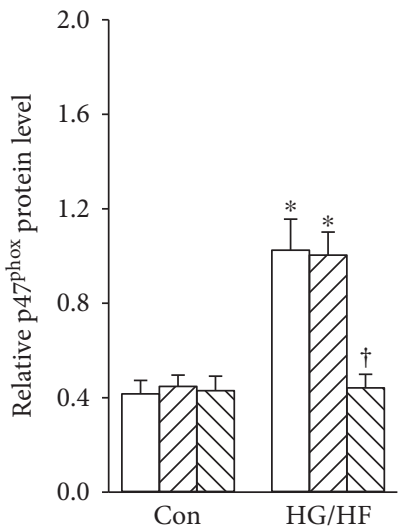

$\square$ Veh

$\square$ Scr shRNA

$\triangle \nabla$ Salusin- $\beta$ shRNA

(f)

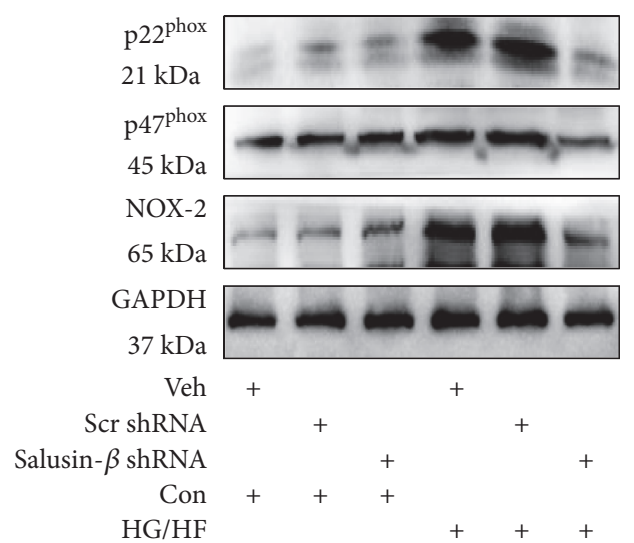

(d)

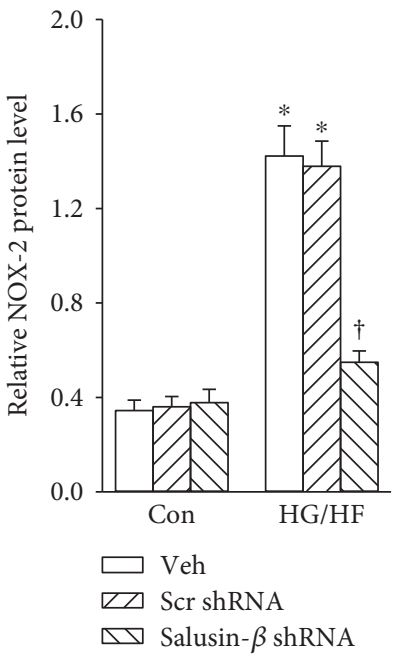

(g)

FIgURE 1: Effects of salusin- $\beta$ knockdown on the oxidative stress of HUVECs. (a, c) Images showing the levels of superoxide anions detected by DHE staining. (b, d) Images showing the ROS levels detected by DCFH-DA staining. (d) Blots showing the protein expressions of $\mathrm{p} 22^{\text {phox }}$, $\mathrm{p} 47^{\text {phox }}$, and NOX-2. Bar graph showing the relative quantification of $\mathrm{p} 22^{\text {phox }}(\mathrm{e}), \mathrm{p} 47^{\text {phox }}(\mathrm{f})$, and NOX-2 (g). Values are mean $\pm \mathrm{SE}$. ${ }^{*} P<0.05$ versus control (Con), ${ }^{\dagger} P<0.05$ versus vehicle (Veh) or scramble (Scr) shRNA. $n=6$ for each group. 
and 1(e)), p47 $7^{\text {phox }}$ (Figures 1(d) and 1(f)), and NOX-2 (Figures 1(d) and 1(g)) were observed in HUVECs response to $\mathrm{HG} / \mathrm{HF}$, and these changes were prevented by salusin- $\beta$ knockdown.

3.3. Salusin- $\beta$ Blockade Retarded Nitrative Stress In Vitro and Improved Endothelial-Dependent Vasorelaxation In Vivo. Incubation of HUVECs with HG/HF promoted NOx production (Figure 2(a)), nitrotyrosine content (Figure 2(b)), but decreased the eNOS activity (Figure 2(c)), and these changes were reversed by partial deletion of salusin- $\beta$. The phosphorylated eNOS level was obviously downregulation, while iNOS expression was markedly increased in HG/HFtreated HUVECs compared with those from vehicle-treated cells (Figure 2(d)). Immunofluorescence to nitrotyrosinepositive cells further demonstrated that nitrotyrosine was significantly increased after HG/HF treatment, which was inhibited by salusin- $\beta$ shRNA (Figure 2(e)). Moreover, in comparison with the aortic segments from control mice, the diabetic aortic segments exhibited impaired Ach-induced vasorelaxation. Interestingly, the aorta from diabetic mice with salusin- $\beta$ silencing exhibited improved ACh-induced vasorelaxation compared with vehicle (Figure $2(\mathrm{f})$ ). The endothelium-independent vasodilator responses to SNP were not different among groups (Figure 2(g)). These data indicated that knockdown of salusin- $\beta$ exerted direct endothelial protective effects.

3.4. Salusin- $\beta$ Blockade Attenuated Inflammation in HG/HFTreated HUVECs. The protein expressions of inflammatory molecules including IL- $1 \beta$, MCP-1, TNF- $\alpha$, and VCAM- 1 were increased in HUVECs response to HG/HF, and silencing of salusin- $\beta$ with shRNA eliminated HG/HF-mediated inflammatory response in HUVECs (Figure 3(a)). The similar results were also observed by ELISA (Figure 3(b)) or real-time PCR assay (Figure 3(c)).

3.5. PPAR $\gamma$ Participated in the Effects of Salusin- $\beta$ Blockade on Nitrative Stress in HUVECs. The protein level of PPAR $\gamma$ was higher in vehicle-treated cells, but it was obviously decreased in HG/HF-incubated HUVECs, and shRNAmediated silencing of salusin- $\beta$ restored the $\operatorname{PPAR} \gamma$ protein expression in HUVECs stimulated by $\mathrm{HG} / \mathrm{HF}$ (Figures 4(a) and 4(b)). These results unveiled that salusin- $\beta$ may act on PPAR $\gamma$ to affect HG/HF-induced endothelial injury. Therefore, we investigated the effect of PPAR $\gamma$ inhibitor T0070907 on endothelial injury in HG/HF-exposed HUVECs. Chronic treatment with T0070907 abolished the protective effects of salusin- $\beta$ blockade on NOx production (Figure 4(c)), nitrotyrosine content (Figure 4(d)), eNOS activity (Figure 4(f)), phosphorylated eNOS level (Figures 4(e) and 4(g)), and iNOS expression (Figures 4(e) and $4(\mathrm{~h})$ ) in HUVECs incubated by HG/HF.

3.6. PPAR $\gamma$ Participated in the Effects of Salusin- $\beta$ Blockade on Oxidative Stress and Inflammation in HUVECs. Preincubation of HUVECs with T0070907 counteracted the effects of salusin- $\beta$ silencing on protein expressions of NADPH oxidase subunits $\mathrm{p} 47^{\text {phox }}$ (Figure S2(a) and S2(b)), p22 $2^{\text {phox }}$ (Figure S2(a) and S2(c)), NOX-2 (Figure S2(a) and S2(d)), and inflammatory molecules including IL- $1 \beta$, MCP-1, TNF- $\alpha$, and VCAM-1(Figure S2(a) and S2(e)) in HUVECs upon HG/HF stimulation. ELISA (Figure S2(f)) or real-time PCR assay (Figure S2(g)) furthermore demonstrated that the protective actions of salusin- $\beta$ blockade on HG/HF-triggered inflammation were diminished by PPAR $\gamma$ inhibitor T0070907. When it came to oxidative stress, DHE (Figure S $3(\mathrm{a})$ and S3(c)) or DCFH-DA (Figure S3(b) and S3(d)) fluorescent staining showed that PPAR $\gamma$ inhibitor T0070907 impeded the beneficial effect of salusin- $\beta$ blockade on HG/ HF-evoked superoxide anions overproduction in HUVECs.

3.7. Salusin- $\beta$ Expression in Aorta of Diabetic Mice In Vivo. In vitro results demonstrated that silencing of salusin- $\beta$ attenuated endothelial cell damage in response to HG/HF. Therefore, mice model of T2DM was made to investigate whether the expression of salusin- $\beta$ was altered in aorta of diabetic mice. There was no significant difference in body weight (Figure 5(a)) or fasting blood glucose (Figure 5(b)) in both control and diabetic mice. The impaired insulin tolerance test (ITT) and glucose tolerance test (GTT) in diabetic mice were not affected by intravenous injection of adenoviral vectors encoding salusin- $\beta$ shRNA (Figure S4), implying that salu$\sin -\beta$ may not be involved in the destructive glucose excursion and insulin sensitivity in diabetic mice. The plasma salusin- $\beta$ (Figure 5(c)), protein (Figure 5(d)), and mRNA (Figure 5(e)) levels of salusin- $\beta$ in aorta were higher in diabetic mice than in control mice, which were obviously reduced by salusin- $\beta$ shRNA in both diabetic mice and control mice. Immunohistochemistry results further established that the upregulated salusin- $\beta$ level in aorta of diabetic mice was decreased by knockdown of salusin- $\beta$ (Figure 5(f)).

3.8. Salusin- $\beta$ Blockade Attenuated Nitrative Stress and Inflammation In Vivo. The production of NOx (Figure 6(a)) and nitrotyrosine level (Figure 6(b)) were increased, but the eNOS activity (Figure 6(c)) was decreased in aortic tissues dissected from diabetic mice, which were prevented by salu$\sin -\beta$ knockdown. The aortic tissues from diabetic mice displayed lower protein level of phosphorylated eNOS, but higher iNOS, IL-1 $\beta$, MCP-1, TNF- $\alpha$, and VCAM- 1 at both protein (Figure 6(d)) and mRNA (Figure 6(e)) levels, which were all reversed by gene silencing of salusin- $\beta$.

3.9. Salusin- $\beta$ Knockdown Reduced ROS Production In Vivo. The aorta from diabetic mice showed obvious changes in NADPH oxidase subunits p22 $2^{\text {phox }}$ (Figures $7(a)$ and 7(b)), $\mathrm{p} 47^{\text {phox }}$ (Figures $7(\mathrm{a})$ and $7(\mathrm{c})$ ), and NOX-2 (Figures $7(\mathrm{a})$ and $7(\mathrm{~d})$ ), which were reversed by salusin- $\beta$ shRNA. The decreased PPAR $\gamma$ protein expression from diabetic aorta was ameliorated by shRNA-mediated silencing of salusin- $\beta$ (Figures 7(a) and 7(e)). DCFH-DA fluorescent staining further confirmed that increased ROS production in diabetic aorta was attenuated by salusin- $\beta$ knockdown (Figures 7(f) and $7(\mathrm{~g}))$.

\section{Discussion}

Endothelial dysfunction is a requisite step in the progression of cardiovascular implications in diabetes [4]. The 


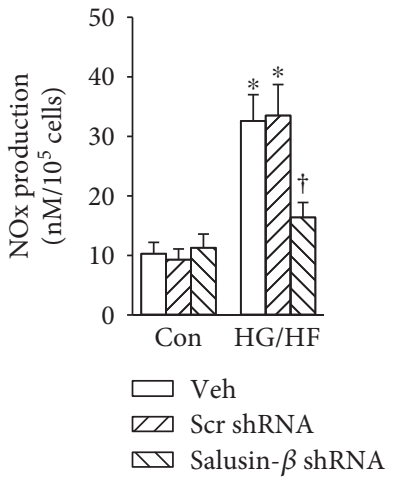

(a)

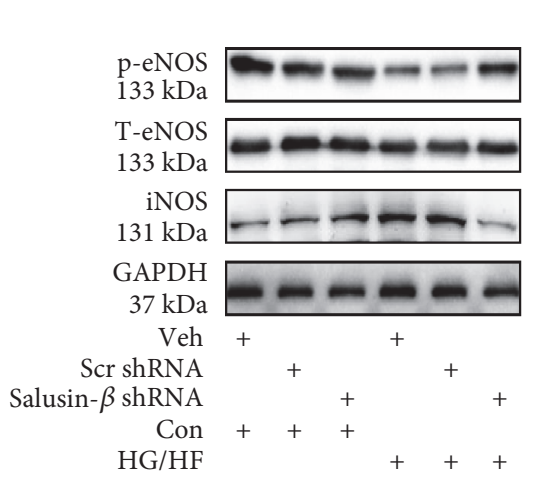

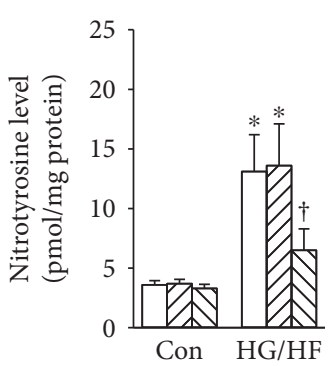

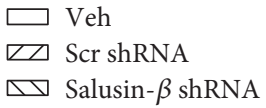

(b)

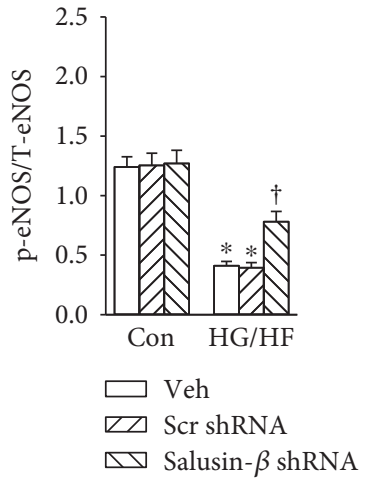

(d)

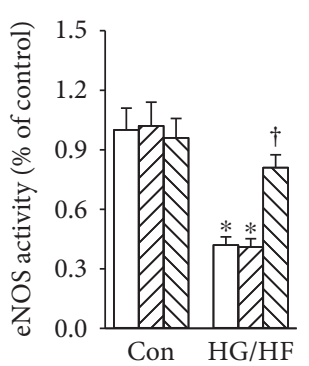

$$
\begin{aligned}
& \square \text { Veh } \\
& \square \text { Scr shRNA } \\
& \square \text { Salusin- } \beta \text { shRNA }
\end{aligned}
$$

(c)

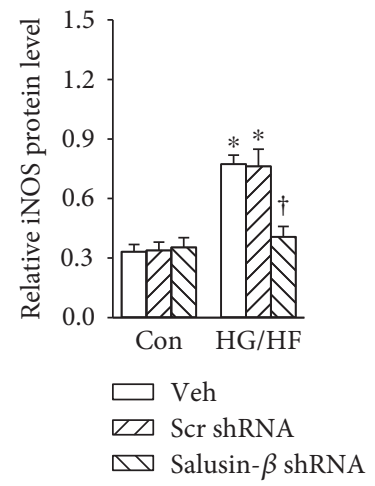

Nitrotyrosine

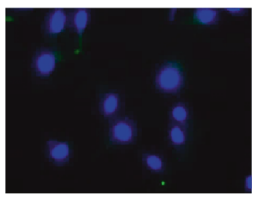

Veh

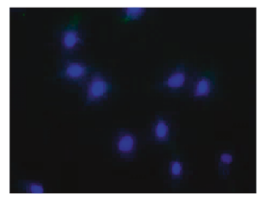

Scr shRNA

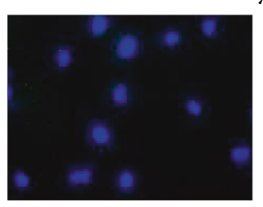

Salusin- $\beta$ shRNA

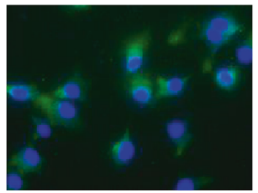

Veh

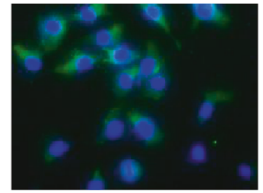

Scr shRNA

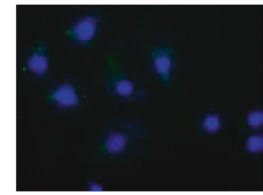

Salusin- $\beta$ shRNA

(e)

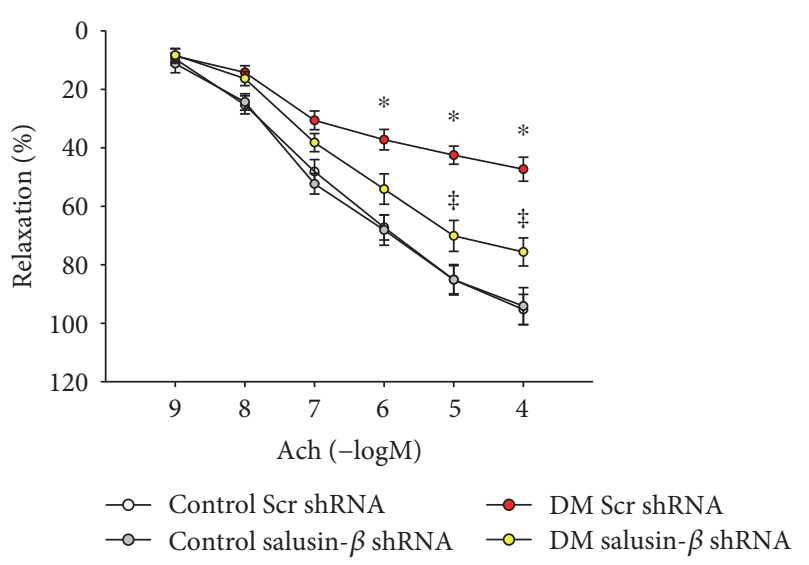

(f)

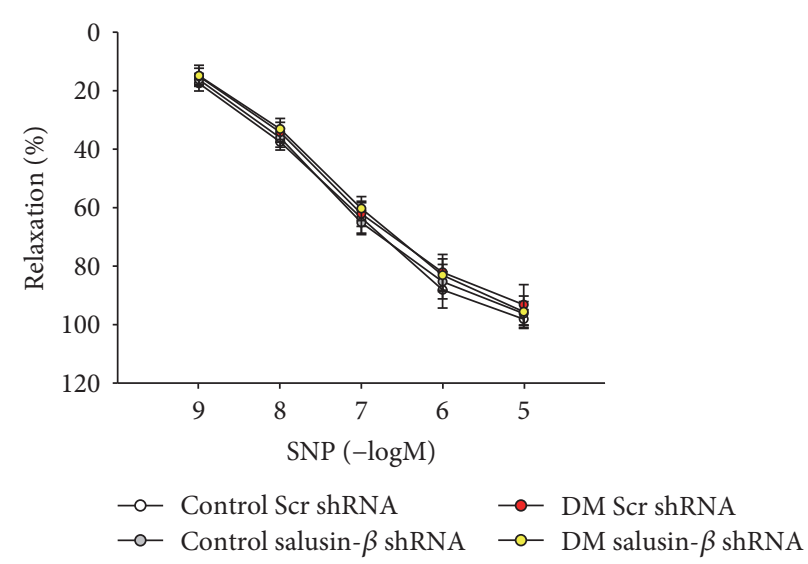

(g)

Figure 2: Effects of salusin- $\beta$ knockdown on the nitrative stress of HUVECs. (a) Total NOx levels. (b) Nitrotyrosine formation. (c) eNOS activity. (d) Blots showing the protein expressions of phosphorylated eNOS and iNOS. (e) The nitrotyrosine formation based on immunofluorescent staining. Salusin- $\beta$ silencing improved the impaired endothelium-dependent vasorelaxation in type 2 diabetic mice (f), but had minimal effects on endothelium-independent vasorelaxation (g). Values are mean \pm SE. ${ }^{*} P<0.05$ versus control (Con) or control scramble (Scr) shRNA, ${ }^{\dagger} P<0.05$ versus vehicle (Veh), scramble (Scr) shRNA or DM scramble (Scr) shRNA. $n=6$ for each group. 


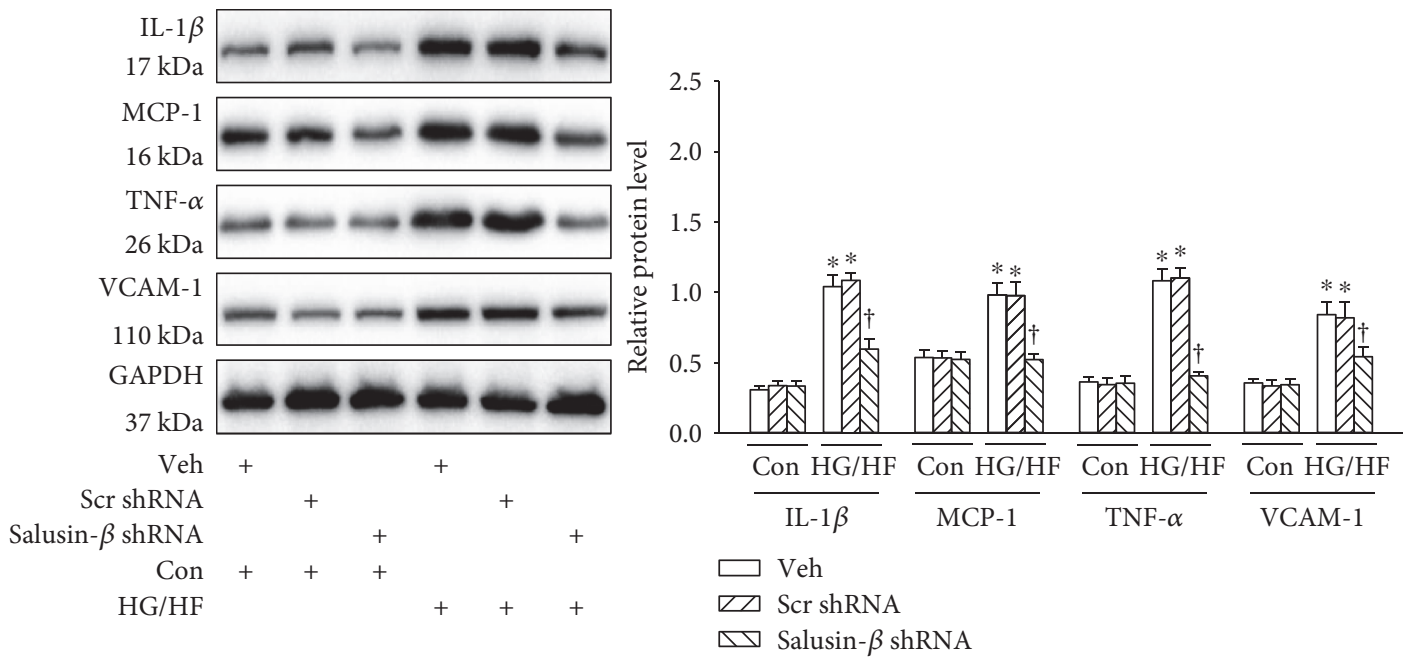

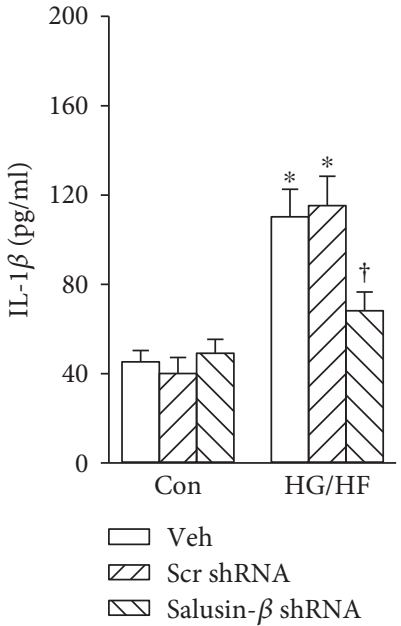

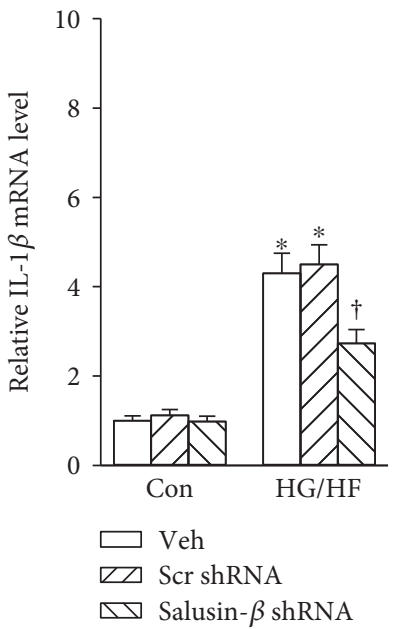

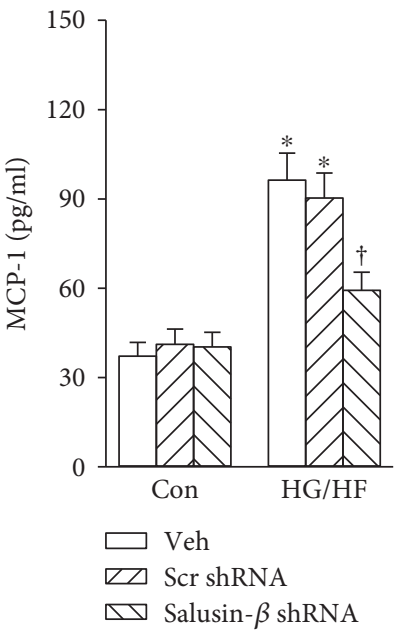
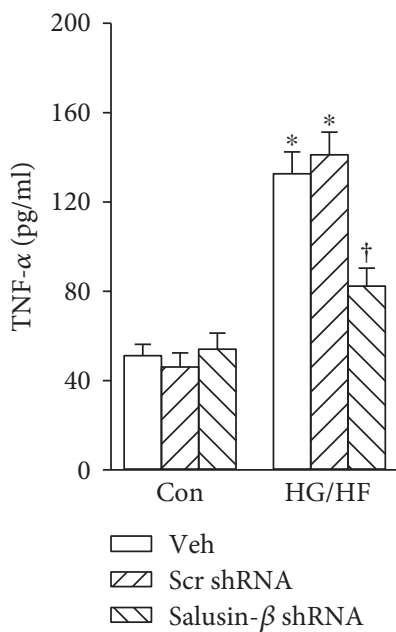

(b)
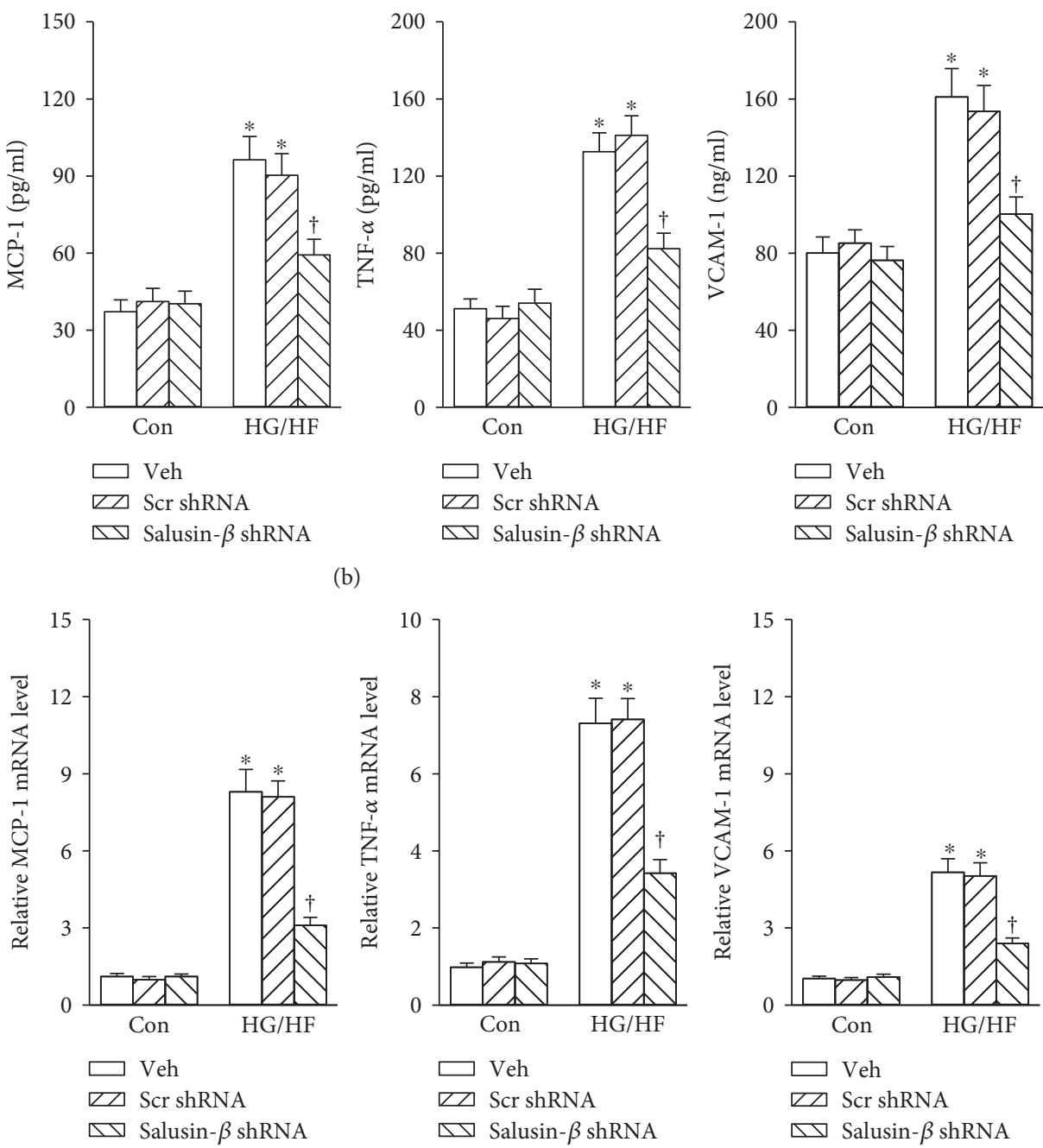

(c) 


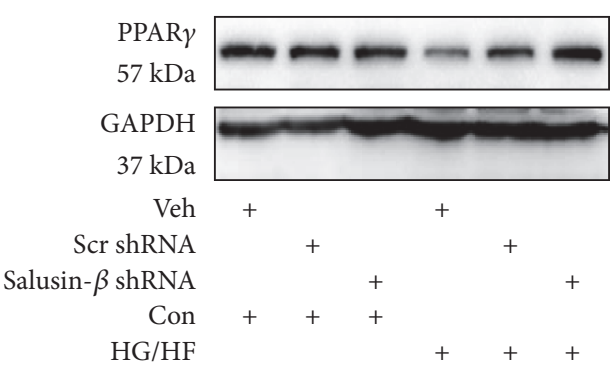

(a)

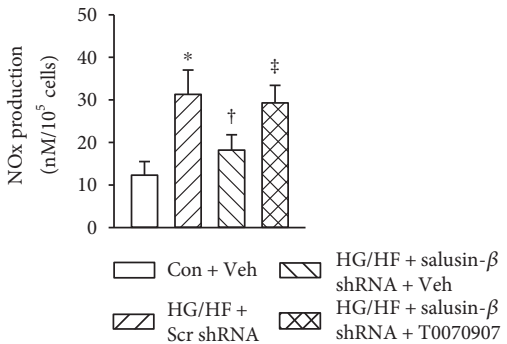

(c)

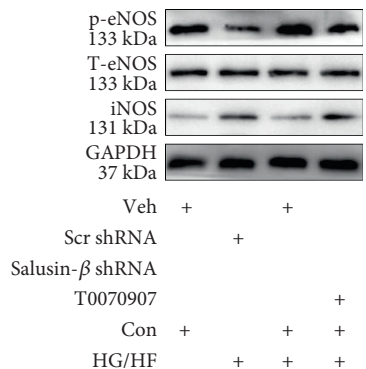

(e)

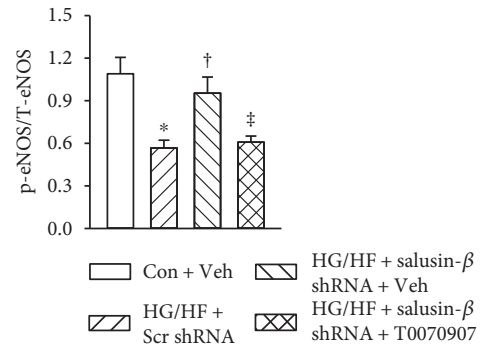

(g)

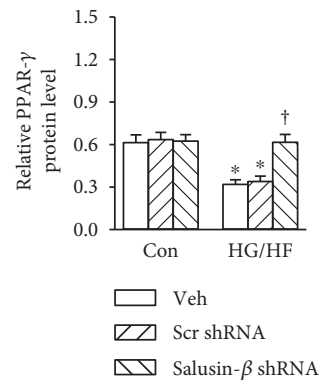

(b)

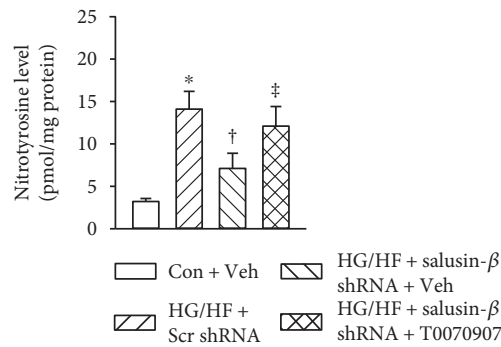

(d)

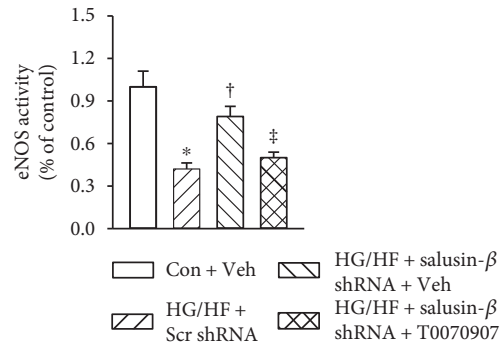

(f)

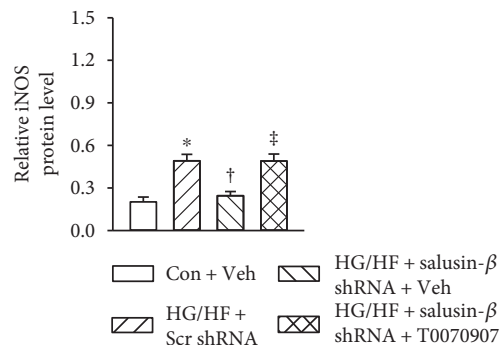

(h)

FIGURE 4: PPAR $\gamma$ participated in the effects of salusin- $\beta$ blockade on nitrative stress in HG/HF-treated HUVECs. HUVECs were pretreated with T0070907 $(10 \mu \mathrm{M})$ for $6 \mathrm{~h}$, and transfected with adenoviral vectors encoding salusin- $\beta$ shRNA or control shRNA for $24 \mathrm{~h}$, and then cultured in control or HG/HF-containing medium for $24 \mathrm{~h}$. (a) Blots showing the protein expressions of PPAR $\gamma$. (b) Total NOx levels. (c) nitrotyrosine formation. (d) Blots showing the protein expressions of phosphorylated eNOS and iNOS. (e) eNOS activity. Bar group showing the relative quantification of phosphorylated eNOS (f) and iNOS (g). Values are mean \pm SE. ${ }^{*} P<0.05$ versus control (Con) + vehicle (Veh), ${ }^{\dagger} P<0.05$ versus $\mathrm{HG} / \mathrm{HF}+$ scramble (Scr) shRNA, ${ }^{\ddagger} P<0.05$ versus $\mathrm{HG} / \mathrm{HF}+\operatorname{salusin}-\beta$ shRNA + vehicle (Veh). $n=6$ for each group.

present study demonstrated that HG/HF induced inflammation response, excessive cellular ROS, and NOx generations accompanied by overexpression of $\operatorname{salusin}-\beta$ in HUVECs. Silencing of salusin- $\beta$ prevented HG/HF-mediated endothelial injury via PPAR $\gamma$ upregulation in HUVECs.
Furthermore, downregulation of salusin- $\beta$ ameliorated endothelium-dependent vasorelaxation of aortic rings from T2DM mice. These results suggested that salusin- $\beta$ knockdown exerted protective effects on endothelial dysfunction in response to DM. 


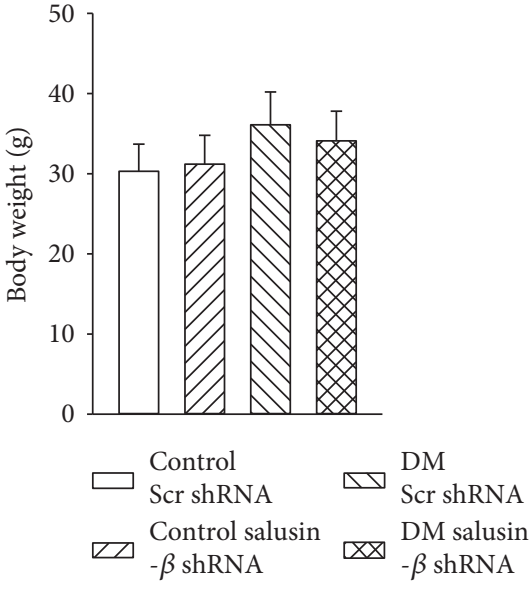

(a)

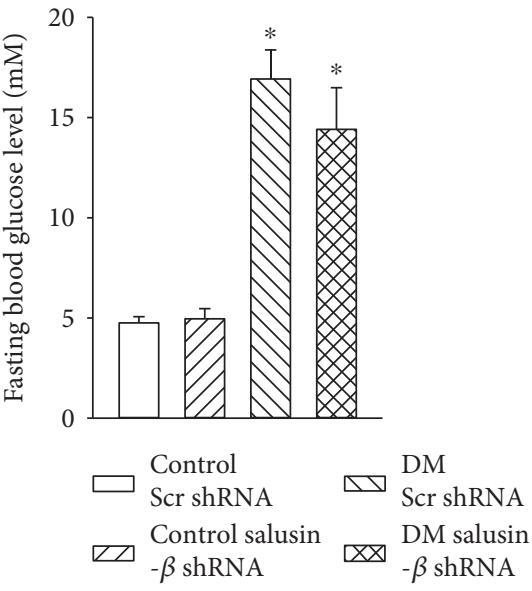

(b)

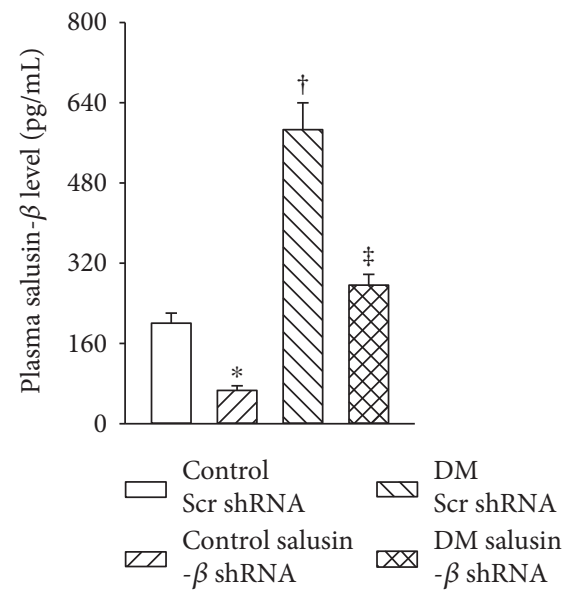

(c)

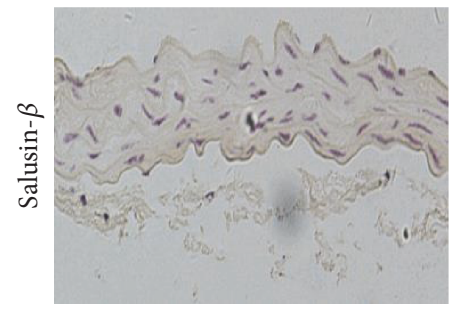

Control Scr shRNA

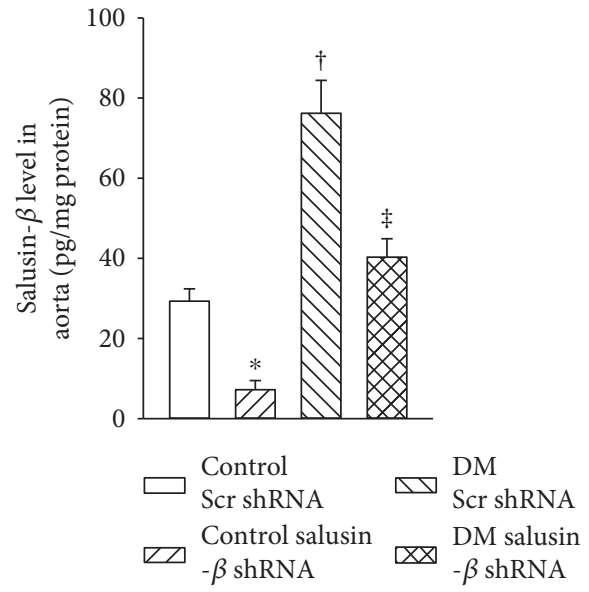

(d)

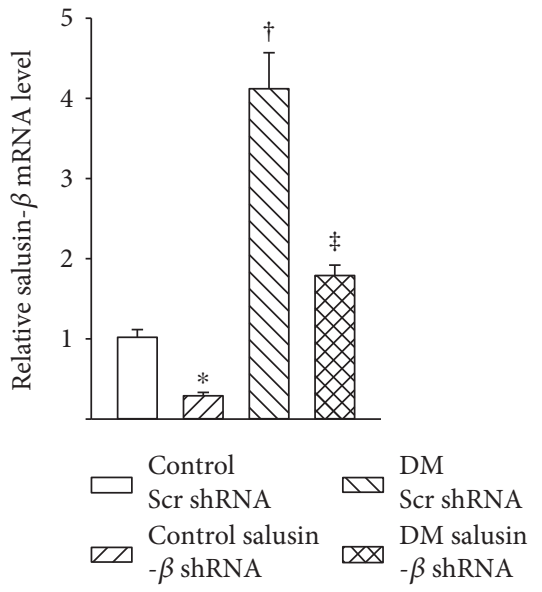

(e)

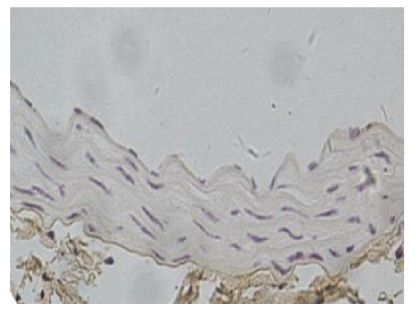

Control salusin- $\beta$ shRNA

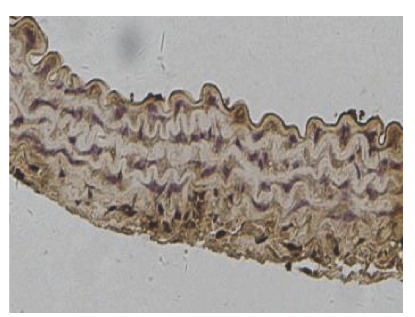

DM Scr shRNA

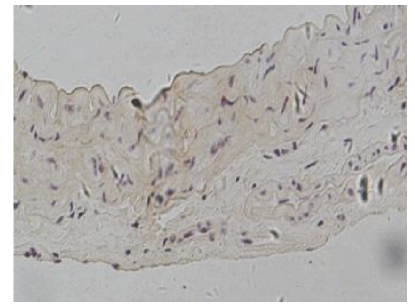

DM salusin- $\beta$ shRNA

(f)

FIGURE 5: Salusin- $\beta$ expression in aorta of diabetic mice in vivo. Salusin- $\beta$ silencing had no effect the bodyweight (a) and fasting blood glucose (b) in type 2 diabetic mice. (c) Plasma salusin- $\beta$ level. (d) Salusin- $\beta$ level in aorta from mice determined with ELISA. (e) Salusin- $\beta$ level in aorta from mice determined with real-time PCR. (f) Salusin- $\beta$ in aorta from mice detected by immunohistochemistry. Values are mean \pm SE. ${ }^{*} P<0.05$ versus control scramble (Scr) shRNA, ${ }^{\dagger} P<0.05$ versus control scramble (Scr) shRNA or control salusin- $\beta$ shRNA, ${ }^{\ddagger} P<0.05$ versus DM scramble (Scr) shRNA. $n=7$ for each group.

Salusin- $\beta$ is identified to be expressed in human, rat, and mouse tissues such as vasculature, central nervous system, and kidneys [40-42]. The circulating salusin- $\beta$ level is increased in diabetic patients [25], and salusin- $\beta$ upregulation was observed in myocardium of diabetic rats [26]. In this study, we found that the salusin- $\beta$ level was increased in both HG/HF-treated HUVECs and aorta from diabetic mice. These results indicated that hyperglycaemia may serve as a stimulator for salusin- $\beta$ expression, and salusin- $\beta$ may play a role in endothelial function in DM.

Hyperglycaemia acts on vascular endothelial cells to produce ROS to interrupt NO bioactivity, endotheliumdependent relaxation, and endothelial dysfunction [43]. The excessive ROS generation plays a functional role in endothelial dysfunction of DM [44]. NADPH oxidases are the major sources of ROS in vascular cells [4]. The NADPH oxidase 


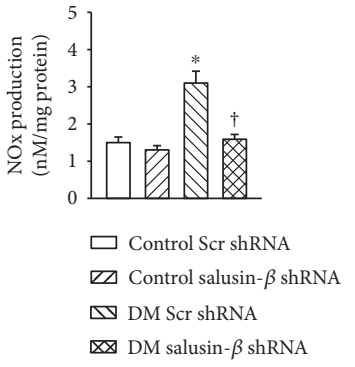

(a)

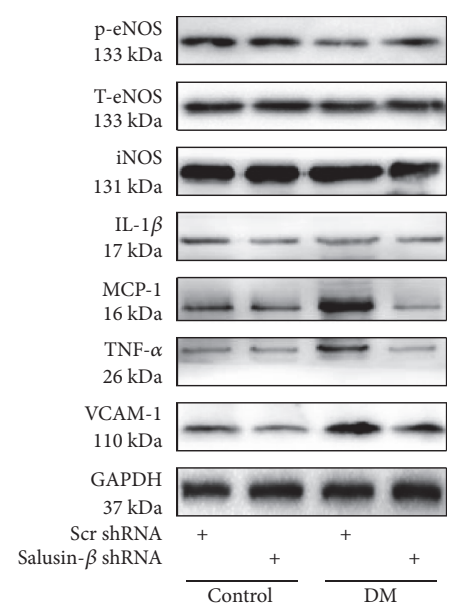

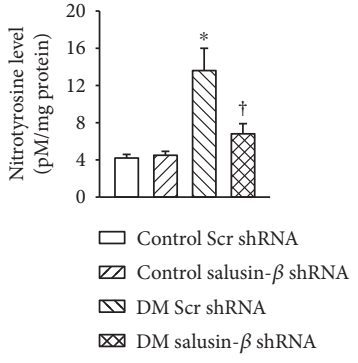

(b)
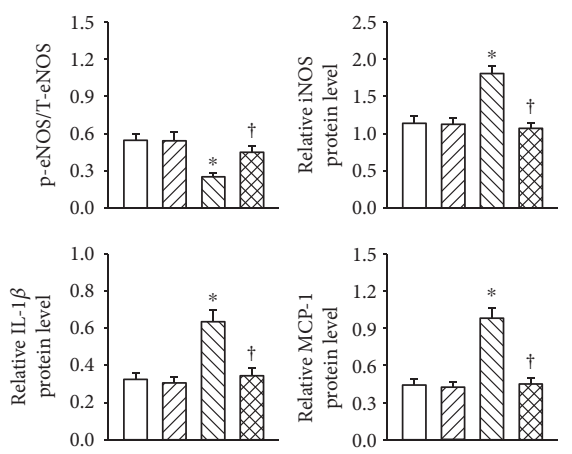

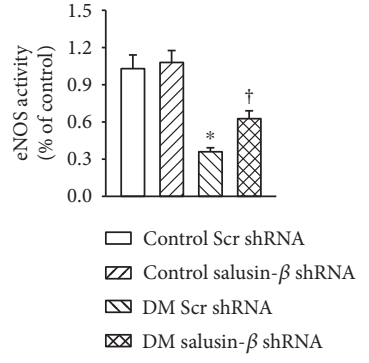

(c)
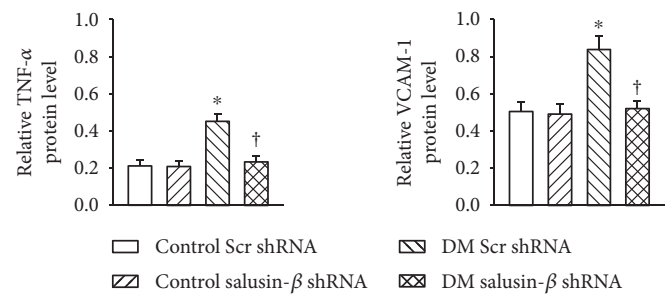

(d)

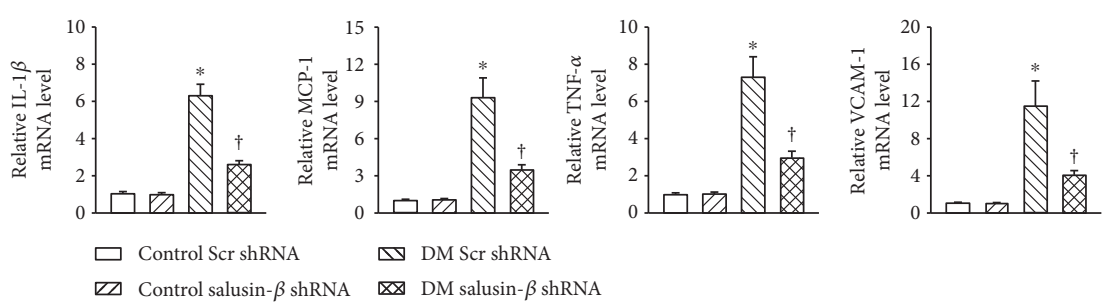

(e)

Figure 6: Salusin- $\beta$ blockade attenuated nitrative stress and inflammation in vivo. Intravenous injection of adenoviral vectors encoding salusin$\beta$ shRNA (Ad-Salusin-shRNA, $2.0 \times 10^{10}$ plaque-forming units) or scramble shRNA (Ad-Scr-shRNA) were carried out 8 weeks after STZ injection. The measurements were made 2 weeks after the first adenovirus transfer. (a) Total NOx levels. (b) nitrotyrosine formation. (c) eNOS activity. (d) Represented blots showing the protein expressions of phosphorylated eNOS, iNOS, IL- $1 \beta$, MCP-1, TNF- $\alpha$, and VCAM-1. (e) Bar group showing the mRNA levels of IL- $1 \beta$, MCP-1, TNF- $\alpha$, and VCAM-1 determined with real-time PCR. Values are mean \pm SE. ${ }^{*} P<0.05$ versus control scramble (Scr) shRNA or control salusin- $\beta$ shRNA, ${ }^{\dagger} P<0.05$ versus DM scramble (Scr) shRNA. $n=7$ for each group.

subunits including NOX-2, p22 $2^{\text {phox }}$, and $\mathrm{p} 47^{\text {phox }}$ are major sources of ROS in the vascular wall [32]. Salusin- $\beta$ promoted vascular injury-induced intimal hyperplasia via NOX-2derived ROS activation, followed by NF- $\kappa$ B/MMP-9 accumulation in VSMCs [16]. Salusin- $\beta$ stimulates ROS production to increase lipid accumulation, monocyte adhesion in VSMCs [17]. Central blockade of salusin- $\beta$ abated increased ROS levels in the paraventricular nucleus of hypertensive rats [45]. We found the increased superoxide anions, NADPH oxidase subunits including NOX-2, p22 $2^{\text {phox }}$, and $\mathrm{p} 47^{\text {phox }}$ in both HG/ HF-incubated HUVECs and aorta from diabetic mice, which were suppressed by shRNA-mediated salusin- $\beta$ silencing. These results indicated that salusin- $\beta$ silencing-induced reduction of ROS may play protective effects on endothelial function. 


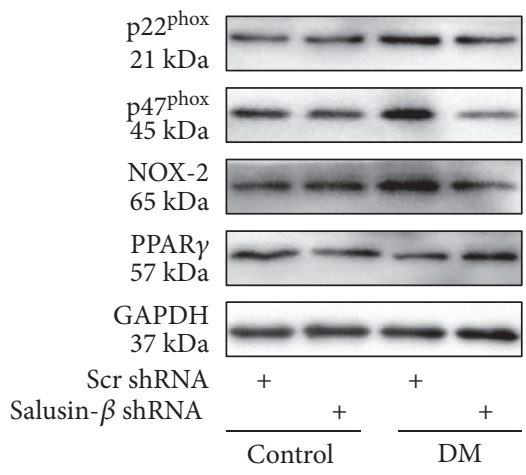

(a)

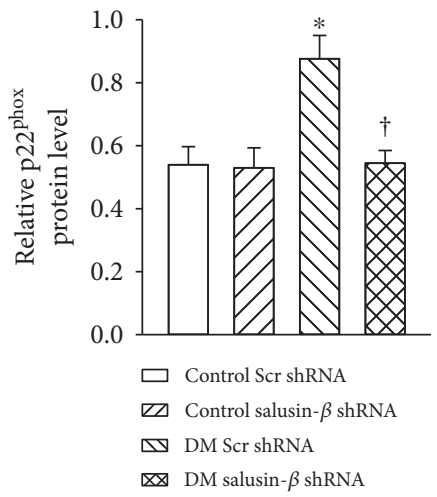

(b)

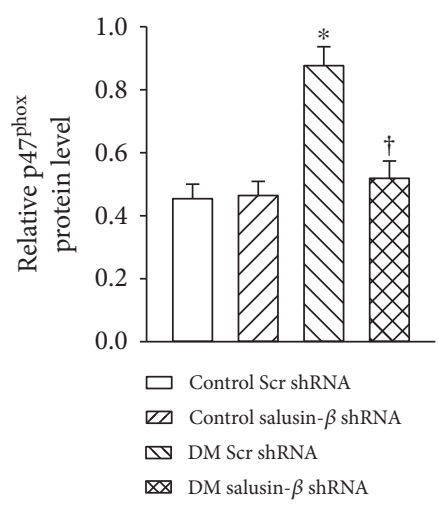

(c)

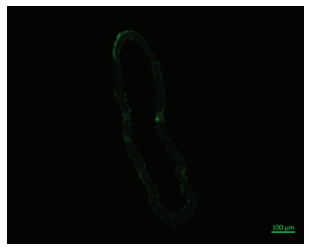

Control Scr shRNA

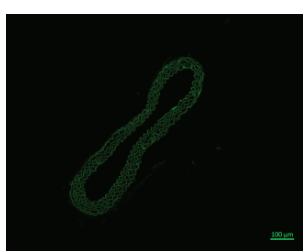

DM Scr shRNA

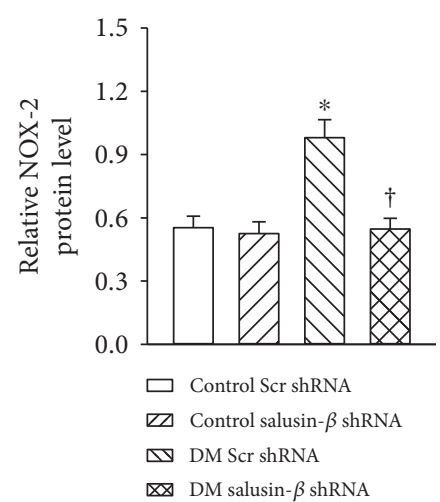

(d)

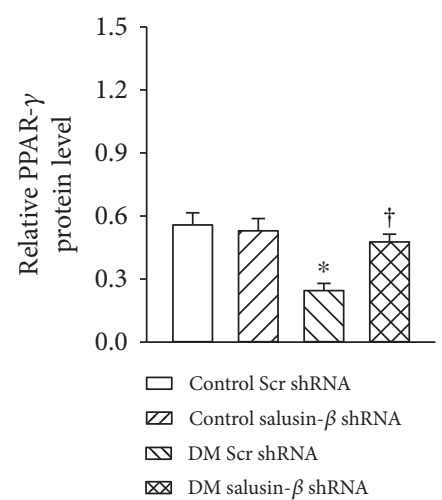

(e)

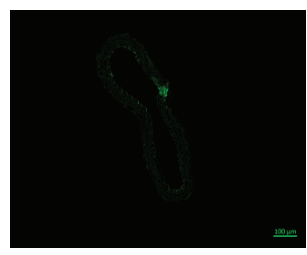

Control salusin- $\beta$ shRNA

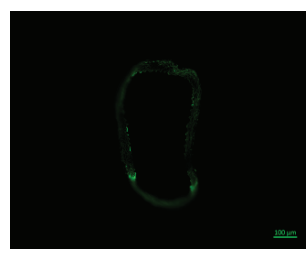

DM salusin- $\beta$ shRNA

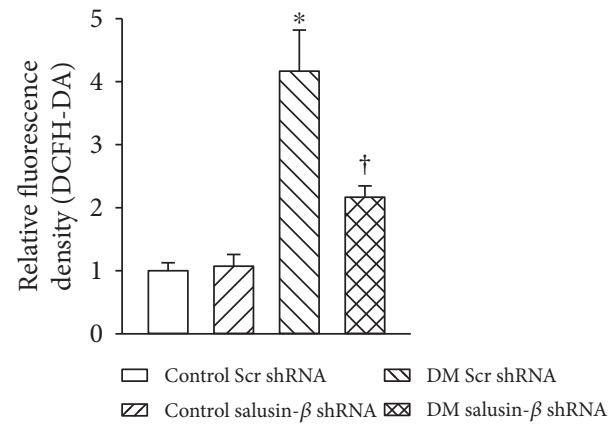

(g)

FIgURE 7: Salusin- $\beta$ knockdown reduced ROS production in vivo. Intravenous injection of adenoviral vectors encoding salusin- $\beta$ shRNA (Ad-salusin-shRNA, $2.0 \times 10^{10}$ plaque-forming units) or scramble shRNA (Ad-Scr-shRNA) were carried out 8 weeks after STZ injection. The measurements were made 2 weeks after the first adenovirus transfer. (a) Blots showing the protein expressions of p22 ${ }^{\text {phox }}, \mathrm{p}^{2} 7^{\text {phox }}$, NOX-2, and PPAR $\gamma$. Bar group showing the protein levels of p $22^{\text {phox }}(\mathrm{b}), \mathrm{p} 47^{\text {phox }}$ (c), NOX-2 (d), and PPAR $\gamma(\mathrm{e})$. (f, g) Representative images of in situ superoxide detection with DCFH-DA staining. Values are mean \pm SE. ${ }^{*} P<0.05$ versus control scramble (Scr) shRNA or control salusin- $\beta$ shRNA, ${ }^{\dagger} P<0.05$ versus DM scramble (Scr) shRNA. $n=7$ for each group.

Hyperglycaemia-triggered ROS induce endothelial cell apoptosis, NO bioactivity reduction, and endotheliumdependent relaxation impairment [46]. The downregulation of eNOS phosphorylation was involved in endothelial dysfunction [47]. Mounting evidence discloses that oxidative/nitrative stresses are critically involved in endothelial injury in T2DM $[48,49]$. It is increasing recognized that low NOx concentrations have protective activities, whereas 
high NOx levels may lead to endothelial dysfunction and tissue injury $[6,9]$. The superoxide can interact with NOx to cause the inactivation of NO and production of a highly cytotoxic molecule peroxynitrite, which plays a crucial role in the pathogenesis of diabetic vascular disease $[9,11]$. We showed that the NOx levels, nitrotyrosine content, iNOS expression were markedly increased, while eNOS phosphorylation and activity was significantly reduced in HG/ HF-treated HUVECs and aortic tissues from diabetic mice, which were eliminated by salusin- $\beta$ knockdown. Moreover, salusin- $\beta$ silencing improved endothelium-dependent vasorelaxation in diabetic aortic segments accompanied by decreased NOx levels, nitrotyrosine content, and iNOS expression and increased eNOS phosphorylation and activity. These results implied that the upregulated iNOS is the primary source of enzymes causing NOx overproduction, silencing of salusin- $\beta$ alleviated nitrative stress through inhibiting the expression of iNOS. The endothelial protective effects of salusin- $\beta$ knockdown in diabetic mice were largely attributed to direct inhibition of nitrative stress.

Inflammation response in endothelial cells is also involved in the pathogenesis of vascular complications of diabetes $[4,49]$. Treatment of HUVECs with salusin- $\beta$ stimulates the expressions of VCAM-1, MCP-1, and IL- $1 \beta$ [50-52]. In the present study, we showed that incubation of HUVECs with HG/HF upregulated the protein and mRNA levels of IL- $1 \beta$, MCP-1, TNF- $\alpha$, and VCAM-1, which were normalized by intervention of salusin- $\beta$. Similar to results from cell experiments in vitro, the increased IL-1 $\beta$, MCP-1, TNF- $\alpha$, and VCAM-1 expressions in aorta form diabetic mice were also obviously attenuated by silencing of salusin$\beta$. These results hinted that salusin- $\beta$ exerted a proinflammatory effect on vascular endothelial cells, and anti-salusin- $\beta$ therapy may afford a novel strategy for treatment of endothelial inflammation in DM.

Peroxisome proliferator-activated receptor gamma $(\operatorname{PPAR} \gamma)$, as a transcriptional regulator of energy balance, is expressed in endothelial cells, and PPAR $\gamma$ has a protective role in endothelial cells beyond its metabolic effects [53]. $\operatorname{PPAR} \gamma$ agonists are expected to ameliorate endothelial dysfunction in diabetes [54]. It is recently unveiled that salusin- $\beta$ negatively regulated PPAR $\gamma$ expressions at protein, $\mathrm{mRNA}$, and gene promoter levels in VSMCs [55]. Our results identified that silencing of salusin- $\beta$ substantially rescued the downregulated PPAR $\gamma$ levels in HUVECs response to HG/ HG medium, and similar results were seen in the aorta from diabetic mice. It is particularly worth noting that PPAR $\gamma$ inhibitor T0070907 abolished the protective effect of salusin- $\beta$ knockdown on the inflammation and oxidative/nitrative stresses in HG/HF-treated HUVECs. Moreover, the decreased PPAR $\gamma$ protein expression from diabetic aorta was ameliorated by shRNA-mediated silencing of salusin- $\beta$. These data suggested that salusin- $\beta$-induced inhibition of PPAR $\gamma$ expression in endothelial cells may be responsible for DM-related endothelial injury. It is important to point out that numerous studies have demonstrated a close link between oxidative/nitrative stresses and inflammation in endothelial dysfunction [56, 57]. Our results showed that DM-induced oxidative/nitrative stresses and inflammation in endothelial cells were all ameliorated by knockdown of salusin- $\beta$. Due to the complexity and comprehensiveness of pathogenesis of DM, we speculated that these phenotypes regulated by salusin- $\beta$ were potentially linked, and thus synergistically participated in endothelial dysfunction in T2DM. Activation of PPAR $\gamma$ is well established to reduce inflammation and oxidative stress and improve endothelial function in diabetic conditions $[58,59]$. Our results verified that $\operatorname{PPAR} \gamma$ was a pivotal effector molecule for salusin- $\beta$, and PPAR $\gamma$ inhibitor T0070907 abolished the protective effects of salusin- $\beta$ knockdown in vitro. We concluded that $\operatorname{PPAR} \gamma$, as a downstream molecule of salusin- $\beta$, specifically modulated oxidative/nitrative stresses and inflammation in endothelial cells.

\section{Conclusions}

Taken together, silencing of salusin- $\beta$ attenuated the HG/HF-induced endothelial cell dysfunction including inflammation and oxidative/nitrative stresses in HUVECs via regulation of $\operatorname{PPAR} \gamma$ (Figure S5). The destructive endothelium-dependent vasorelaxation of aortic rings from T2DM mice were obviously improved by knockdown of salusin- $\beta$. Our results provided the evidence that salusin- $\beta$ was closely related with endothelial dysfunction in T2DM.

\section{Conflicts of Interest}

The authors declare that they have no competing interest.

\section{Authors' Contributions}

Hai-Jian Sun, Dan Chen, Pei-Yao Wang, and Ming-Yu Wan contributed to the conception and design of the research. Hai-Jian Sun, Dan Chen, Pei-Yao Wang, and Ming-Yu Wan performed the experiments. Hai-Jian Sun, Chen-Xing Zhang, and Zhi-Xuan Zhang analyzed the data. Hai-Jian Sun, Dan Chen, Pei-Yao Wang, Wei Lin, and Ming-Yu Wan interpreted the results of the experiments. Hai-Jian Sun prepared the figures. Hai-Jian Sun and Dan Chen drafted the manuscript. Hai-Jian Sun, Dan Chen, Pei-Yao Wang, Ming-Yu Wan, and Feng Zhang edited and revised the manuscript. Hai-Jian Sun, Dan Chen, Pei-Yao Wang, Ming-Yu Wan, Chen-Xing Zhang, Zhi-Xuan Zhang, Wei Lin, and Feng Zhang approved the final version of the manuscript. Hai-Jian Sun, Dan Chen, Pei-Yao Wang, and Ming-Yu Wan contributed equally to this work.

\section{Acknowledgments}

This work was supported by NSFC (81300194 and 81700364), Jiangsu Natural Science Foundation (BK20170179), and Fundamental Research Funds for the Central Universities (JUSRP11745) and projects funded by China Postdoctoral Science Foundation (2017M611688) and by Jiangsu Postdoctoral Science Foundation (1701062C). 


\section{References}

[1] G. Danaei, M. M. Finucane, Y. Lu et al., "National, regional, and global trends in fasting plasma glucose and diabetes prevalence since 1980: systematic analysis of health examination surveys and epidemiological studies with 370 country-years and 2.7 million participants," The Lancet, vol. 378, no. 9785, pp. 31-40, 2011.

[2] C. E. Tabit, S. M. Shenouda, M. Holbrook et al., "Protein kinase C- $\beta$ contributes to impaired endothelial insulin signaling in humans with diabetes mellitus," Circulation, vol. 127, no. 1, pp. 86-95, 2013.

[3] S. P. Gray and K. Jandeleit-Dahm, "The pathobiology of diabetic vascular complications-cardiovascular and kidney disease," Journal of Molecular Medicine, vol. 92, no. 5, pp. 441-452, 2014.

[4] H. J. Sun, B. Hou, X. Wang, X. X. Zhu, K. X. Li, and L. Y. Qiu, "Endothelial dysfunction and cardiometabolic diseases: role of long non-coding RNAs," Life Sciences, vol. 167, pp. 6-11, 2016.

[5] G. X. Shen, "Oxidative stress and diabetic cardiovascular disorders: roles of mitochondria and NADPH oxidase," Canadian Journal of Physiology and Pharmacology, vol. 88, no. 3, pp. 241-248, 2010.

[6] R. Li, W. Q. Wang, H. Zhang et al., “Adiponectin improves endothelial function in hyperlipidemic rats by reducing oxidative/nitrative stress and differential regulation of eNOS/iNOS activity," American Journal of Physiology - Endocrinology and Metabolism, vol. 293, no. 6, pp. E1703-E1708, 2007.

[7] V. Lubrano and S. Balzan, "LOX-1 and ROS, inseparable factors in the process of endothelial damage," Free Radical Research, vol. 48, no. 8, pp. 841-848, 2014.

[8] L. Gao and G. E. Mann, "Vascular NAD(P)H oxidase activation in diabetes: a double-edged sword in redox signalling," Cardiovascular Research, vol. 82, no. 1, pp. 9-20, 2009.

[9] D. Zhu, H. Wang, J. Zhang et al., "Irisin improves endothelial function in type 2 diabetes through reducing oxidative/nitrative stresses," Journal of Molecular and Cellular Cardiology, vol. 87, pp. 138-147, 2015.

[10] A. Konior, A. Schramm, M. Czesnikiewicz-Guzik, and T. J. Guzik, "NADPH oxidases in vascular pathology," Antioxidants \& Redox Signaling, vol. 20, no. 17, pp. 2794-2814, 2014.

[11] L. Gliemann, M. Nyberg, and Y. Hellsten, "Nitric oxide and reactive oxygen species in limb vascular function: what is the effect of physical activity?," Free Radical Research, vol. 48, no. 1, pp. 71-83, 2014.

[12] H. K. Park, M. K. Kwak, H. J. Kim, and R. S. Ahima, "Linking resistin, inflammation, and cardiometabolic diseases," The Korean Journal of Internal Medicine, vol. 32, no. 2, pp. 239247, 2017.

[13] M. A. Potenza, C. Nacci, M. A. De Salvia, L. Sgarra, M. Collino, and M. Montagnani, "Targeting endothelial metaflammation to counteract diabesity cardiovascular risk: current and perspective therapeutic options," Pharmacological Research, vol. 120, pp. 226-241, 2017.

[14] M. Shichiri, S. Ishimaru, T. Ota, T. Nishikawa, T. Isogai, and Y. Hirata, "Salusins: newly identified bioactive peptides with hemodynamic and mitogenic activities," Nature Medicine, vol. 9, no. 9, pp. 1166-1172, 2003.

[15] H. J. Sun, T. Y. Liu, F. Zhang et al., "Salusin- $\beta$ contributes to vascular remodeling associated with hypertension via promoting vascular smooth muscle cell proliferation and vascular fibrosis," Biochimica et Biophysica Acta (BBA) - Molecular Basis of Disease, vol. 1852, no. 9, pp. 1709-1718, 2015.

[16] H. J. Sun, M. X. Zhao, X. S. Ren et al., "Salusin- $\beta$ promotes vascular smooth muscle cell migration and intimal hyperplasia after vascular injury via ROS/NFkB/MMP-9 pathway," Antioxidants \& Redox Signaling, vol. 24, no. 18, pp. 10451057, 2016.

[17] H. J. Sun, M. X. Zhao, T. Y. Liu et al., "Salusin- $\beta$ induces foam cell formation and monocyte adhesion in human vascular smooth muscle cells via miR155/NOX2/NFkB pathway," Scientific Reports, vol. 6, article 23596, 2016.

[18] L. Niepolski and A. E. Grzegorzewska, "Salusins and adropin: new peptides potentially involved in lipid metabolism and atherosclerosis," Advances in Medical Sciences, vol. 61, no. 2, pp. 282-287, 2016.

[19] U. Kolakowska, W. Olanski, and A. Wasilewska, "Salusins in hypertension and related cardiovascular diseases," Current Drug Metabolism, vol. 17, no. 8, pp. 827-833, 2016.

[20] W. W. Chen, H. J. Sun, F. Zhang et al., "Salusin- $\beta$ in paraventricular nucleus increases blood pressure and sympathetic outflow via vasopressin in hypertensive rats," Cardiovascular Research, vol. 98, no. 3, pp. 344-351, 2013.

[21] H. J. Sun, L. L. Zhang, Z. D. Fan et al., "Superoxide anions involved in sympathoexcitation and pressor effects of salusin- $\beta$ in paraventricular nucleus in hypertensive rats," Acta Physiologica, vol. 210, no. 3, pp. 534-545, 2014.

[22] L. L. Zhang, L. Ding, F. Zhang et al., "Salusin- $\beta$ in rostral ventrolateral medulla increases sympathetic outflow and blood pressure via superoxide anions in hypertensive rats," Journal of Hypertension, vol. 32, no. 5, pp. 1059-1067, 2014.

[23] F. Yu, J. Zhao, J. Yang et al., "Salusins promote cardiomyocyte growth but does not affect cardiac function in rats," Regulatory Peptides, vol. 122, no. 3, pp. 191-197, 2004.

[24] T. Xu, Z. Zhang, T. Liu et al., "Salusin- $\beta$ contributes to vascular inflammation associated with pulmonary arterial hypertension in rats," The Journal of Thoracic and Cardiovascular Surgery, vol. 152, no. 4, pp. 1177-1187, 2016.

[25] K. Fujimoto, A. Hayashi, Y. Kamata et al., "Circulating levels of human salusin- $\beta$, a potent hemodynamic and atherogenesis regulator," PLoS One, vol. 8, no. 10, article e76714, 2013.

[26] M. X. Zhao, B. Zhou, L. Ling et al., "Salusin- $\beta$ contributes to oxidative stress and inflammation in diabetic cardiomyopathy," Cell Death and Disease, vol. 8, no. 3, article e2690, 2017.

[27] X. Zhu, Y. Zhou, W. Cai, H. Sun, and L. Qiu, "Salusin- $\beta$ mediates high glucose-induced endothelial injury via disruption of AMPK signaling pathway," Biochemical and Biophysical Research Communications, vol. 491, no. 2, pp. 515-521, 2017.

[28] T. Y. Liu, C. X. Shi, R. Gao et al., "Irisin inhibits hepatic gluconeogenesis and increases glycogen synthesis via the PI3K/Akt pathway in type 2 diabetic mice and hepatocytes," Clinical Science, vol. 129, no. 10, pp. 839-850, 2015.

[29] M. Zhang, X. Y. Lv, J. Li, Z. G. Xu, and L. Chen, “The characterization of high-fat diet and multiple low-dose streptozotocin induced type 2 diabetes rat model," Experimental Diabetes Research, vol. 2008, Article ID 704045, 9 pages, 2008.

[30] C. X. Shi, M. X. Zhao, X. D. Shu et al., “ $\beta$-aminoisobutyric acid attenuates hepatic endoplasmic reticulum stress and glucose/ lipid metabolic disturbance in mice with type 2 diabetes," Scientific Reports, vol. 6, article 21924, 2016.

[31] J. Zhang, L. Xia, F. Zhang et al., "A novel mechanism of diabetic vascular endothelial dysfunction: hypoadiponectinemia- 
induced NLRP3 inflammasome activation," Biochimica et Biophysica Acta (BBA) - Molecular Basis of Disease, vol. 1863, no. 6, pp. 1556-1567, 2017.

[32] A. M. Quintela, R. Jimenez, M. Gomez-Guzman et al., "Activation of peroxisome proliferator-activated receptor$\beta /-\delta(\operatorname{PPAR} \beta / \delta)$ prevents endothelial dysfunction in type 1 diabetic rats," Free Radical Biology and Medicine, vol. 53, no. 4, pp. 730-741, 2012.

[33] M. A. Silva, T. Bruder-Nascimento, S. B. Cau et al., "Spironolactone treatment attenuates vascular dysfunction in type 2 diabetic mice by decreasing oxidative stress and restoring NO/GC signaling," Frontiers in Physiology, vol. 6, p. 269, 2015.

[34] J. D. Symons, S. L. McMillin, C. Riehle et al., "Contribution of insulin and Akt1 signaling to endothelial nitric oxide synthase in the regulation of endothelial function and blood pressure," Circulation Research, vol. 104, no. 9, pp. 1085-1094, 2009.

[35] H. J. Sun, X. S. Ren, X. Q. Xiong et al., "NLRP3 inflammasome activation contributes to VSMC phenotypic transformation and proliferation in hypertension," Cell Death and Disease, vol. 8, no. 10, article e3074, 2017.

[36] M. H. Bao, J. M. Li, H. Q. Luo et al., "NF- $\kappa$ B-regulated miR-99a modulates endothelial cell inflammation," Mediators of Inflammation, vol. 2016, Article ID 5308170, 9 pages, 2016.

[37] H. Sun, X. Zhu, W. Cai, and L. Qiu, "Hypaphorine attenuates lipopolysaccharide-induced endothelial inflammation via regulation of TLR4 and PPAR- $\gamma$ dependent on PI3K/Akt/mTOR signal pathway," International Journal of Molecular Sciences, vol. 18, no. 4, 2017.

[38] W. Zhu, B. Yang, H. Fu et al., "Flavone inhibits nitric oxide synthase (NOS) activity, nitric oxide production and protein S-nitrosylation in breast cancer cells," Biochemical and Biophysical Research Communications, vol. 458, no. 3, pp. 590595, 2015.

[39] L. Xue, F. Xu, L. Meng et al., "Acetylation-dependent regulation of mitochondrial ALDH2 activation by SIRT3 mediates acute ethanol-induced eNOS activation," FEBS Letters, vol. 586, no. 2, pp. 137-142, 2012.

[40] F. Takenoya, T. Hori, H. Kageyama et al., "Coexistence of salusin and vasopressin in the rat hypothalamo-hypophyseal system," Neuroscience Letters, vol. 385, no. 2, pp. 110-113, 2005.

[41] N. Suzuki, M. Shichiri, T. Tateno, K. Sato, and Y. Hirata, "Distinct systemic distribution of salusin- $\alpha$ and salusin- $\beta$ in the rat," Peptides, vol. 32, no. 4, pp. 805-810, 2011.

[42] K. Sato, T. Koyama, T. Tateno, Y. Hirata, and M. Shichiri, "Presence of immunoreactive salusin- $\alpha$ in human serum and urine," Peptides, vol. 27, no. 11, pp. 2561-2566, 2006.

[43] F. Paneni, P. Mocharla, A. Akhmedov et al., "Gene silencing of the mitochondrial adaptor $\mathrm{p} 66^{\mathrm{Shc}}$ suppresses vascular hyperglycemic memory in diabetes," Circulation Research, vol. 111, no. 3, pp. 278-289, 2012.

[44] G. E. McVeigh and J. N. Cohn, "Endothelial dysfunction and the metabolic syndrome," Current Diabetes Reports, vol. 3, no. 1, pp. 87-92, 2003.

[45] H. B. Li, D. N. Qin, K. Cheng et al., "Central blockade of salu$\sin \beta$ attenuates hypertension and hypothalamic inflammation in spontaneously hypertensive rats," Scientific Reports, vol. 5, article 11162, 2015.

[46] T. Inoguchi, P. Li, F. Umeda et al., "High glucose level and free fatty acid stimulate reactive oxygen species production through protein kinase $\mathrm{C}$-dependent activation of $\mathrm{NAD}(\mathrm{P}) \mathrm{H}$ oxidase in cultured vascular cells," Diabetes, vol. 49, no. 11, pp. 1939-1945, 2000.

[47] D. Qi, X. Tang, J. He et al., “Omentin protects against LPS-induced ARDS through suppressing pulmonary inflammation and promoting endothelial barrier via an Akt/eNOSdependent mechanism," Cell Death and Disease, vol. 7, no. 9, article e2360, 2016.

[48] F. Paneni, J. A. Beckman, M. A. Creager, and F. Cosentino, "Diabetes and vascular disease: pathophysiology, clinical consequences, and medical therapy: part I," European Heart Journal, vol. 34, no. 31, pp. 2436-2446, 2013.

[49] A. Lerman and A. M. Zeiher, "Endothelial function: cardiac events," Circulation, vol. 111, no. 3, pp. 363-368, 2005.

[50] T. Koya, T. Miyazaki, T. Watanabe et al., "Salusin- $\beta$ accelerates inflammatory responses in vascular endothelial cells via NF- $\kappa \mathrm{B}$ signaling in LDL receptor-deficient mice in vivo and HUVECs in vitro," American Journal of Physiology - Heart and Circulatory Physiology, vol. 303, no. 1, pp. H96-105, 2012.

[51] C. H. Zhou, L. Liu, L. Liu et al., "Salusin- $\beta$ not salusin- $\alpha$ promotes vascular inflammation in ApoE-deficient mice via the $\mathrm{I}-\kappa \mathrm{B} \alpha / \mathrm{NF}-\kappa \mathrm{B}$ pathway," PLoS One, vol. 9, no. 3, article e91468, 2014.

[52] C. H. Zhou, J. Pan, H. Huang et al., "Salusin- $\beta$, but not salusin- $\alpha$, promotes human umbilical vein endothelial cell inflammation via the p38 MAPK/JNK-NF- $\kappa$ B pathway," PLoS One, vol. 9, no. 9, article e107555, 2014.

[53] T. Kanda, J. D. Brown, G. Orasanu et al., "PPAR $\gamma$ in the endothelium regulates metabolic responses to high-fat diet in mice," The Journal of Clinical Investigation, vol. 119, no. 1, pp. 110-124, 2009.

[54] E. Verrier, L. Wang, C. Wadham et al., "PPAR $\gamma$ agonists ameliorate endothelial cell activation via inhibition of diacylglycerol-protein kinase $\mathrm{C}$ signaling pathway: role of diacylglycerol kinase," Circulation Research, vol. 94, no. 11, pp. 1515-1522, 2004.

[55] X. Xu, M. He, T. Liu, Y. Zeng, and W. Zhang, "Effect of salusin- $\beta$ on peroxisome proliferator-activated receptor gamma gene expression in vascular smooth muscle cells and its possible mechanism," Cellular Physiology and Biochemistry, vol. 36, no. 6, pp. 2466-2479, 2015.

[56] B. J. Goldstein, R. G. Scalia, and X. L. Ma, "Protective vascular and myocardial effects of adiponectin," Nature Clinical Practice Cardiovascular Medicine, vol. 6, no. 1, pp. 27-35, 2009.

[57] M. Kunitomo, Y. Yamaguchi, S. Kagota, and K. Otsubo, "Beneficial effect of coenzyme Q10 on increased oxidative and nitrative stress and inflammation and individual metabolic components developing in a rat model of metabolic syndrome," Journal of Pharmacological Sciences, vol. 107, no. 2, pp. 128-137, 2008.

[58] E. A. Ivanova, V. A. Myasoedova, A. A. Melnichenko, and A. N. Orekhov, "Peroxisome proliferator-activated receptor (PPAR) gamma agonists as therapeutic agents for cardiovascular disorders: focus on atherosclerosis," Current Pharmaceutical Design, vol. 23, no. 7, pp. 1119-1124, 2017.

[59] M. Olukman, E. D. Sezer, S. Ulker, E. Y. Sozmen, and G. M. Cinar, "Fenofibrate treatment enhances antioxidant status and attenuates endothelial dysfunction in streptozotocininduced diabetic rats," Experimental Diabetes Research, vol. 2010, Article ID 828531, 10 pages, 2010. 


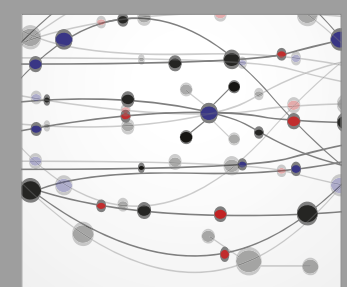

The Scientific World Journal
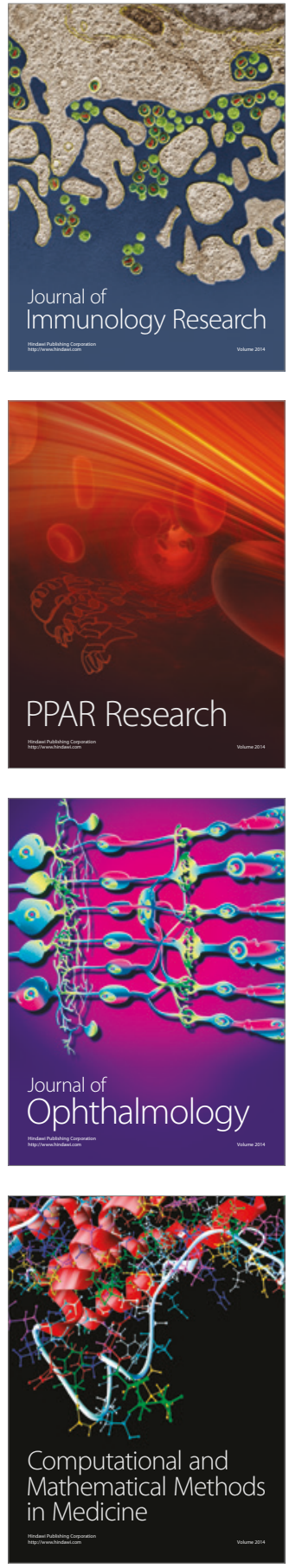

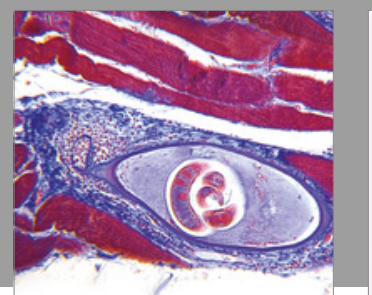

Gastroenterology Research and Practice
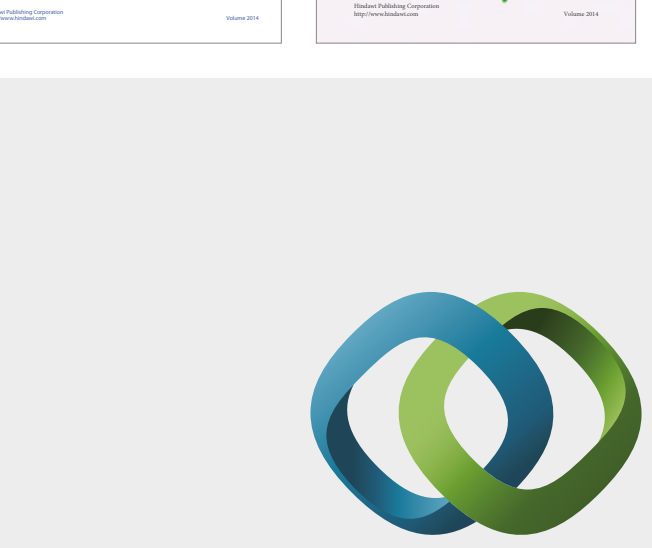

\section{Hindawi}

Submit your manuscripts at

https://www.hindawi.com
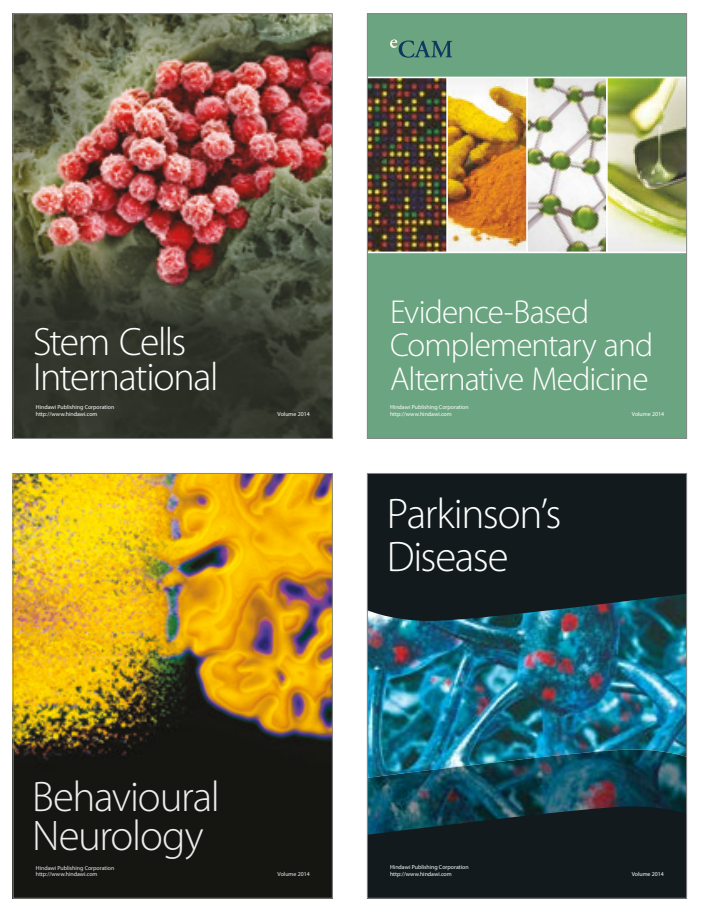
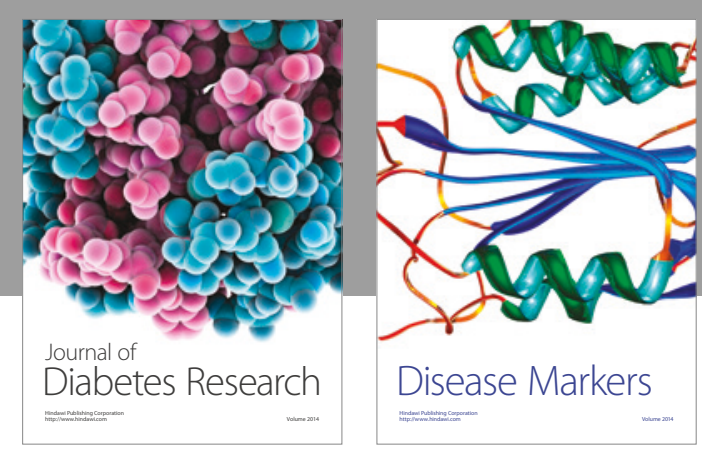

Disease Markers
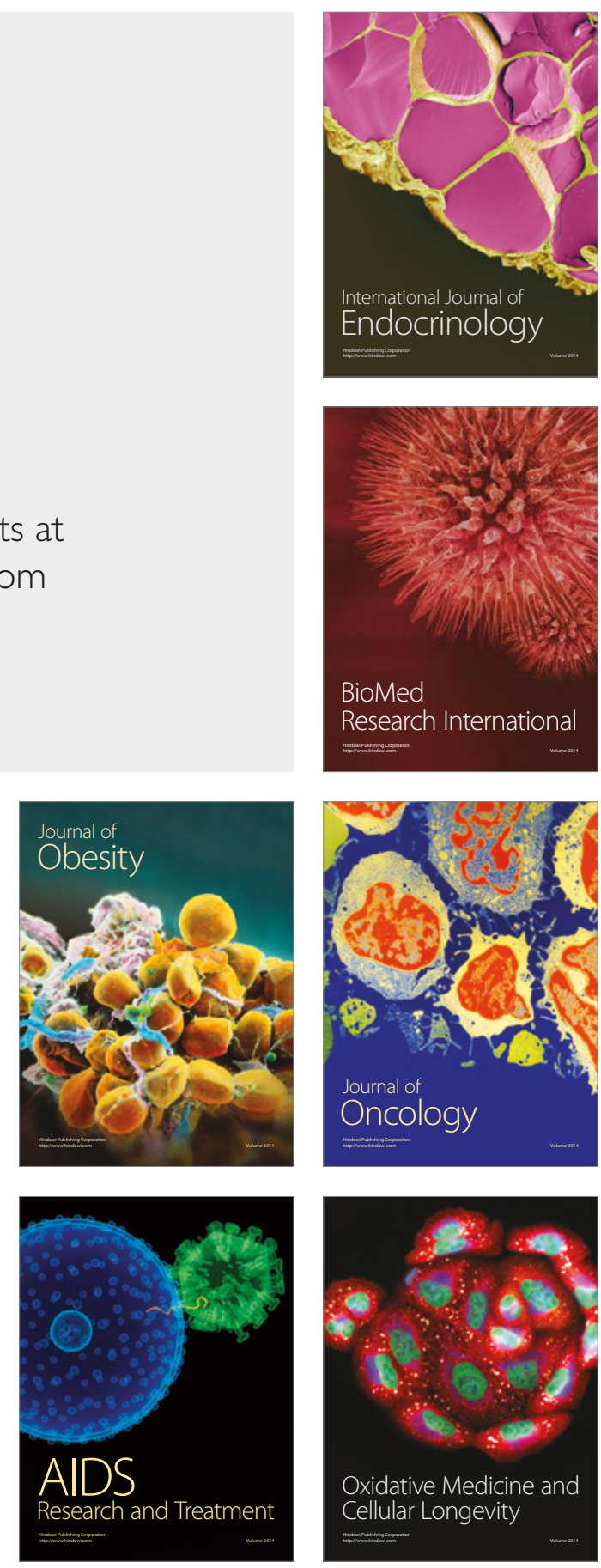